\title{
Ion Channel Function During Oocyte Maturation and Fertilization
}

\author{
Ingrid Carvacho ${ }^{1 *}$, Matthias Piesche ${ }^{2}$, Thorsten J. Maier ${ }^{3}$ and Khaled Machaca ${ }^{4}$ \\ ${ }^{1}$ Department of Biology and Chemistry, Faculty of Basic Sciences, Universidad Católica del Maule, Talca, Chile, ${ }^{2}$ Biomedical \\ Research Laboratories, Medicine Faculty, Universidad Católica del Maule, Talca, Chile, ${ }^{3}$ Department of Anesthesiology, \\ Intensive Care Medicine and Pain Therapy, Goethe-University Hospital, Frankfurt, Germany, ${ }^{4}$ Department of Physiology and \\ Biophysics, Weill Cornell-Medicine-Qatar, Education City, Qatar Foundation, Doha, Qatar
}

\section{OPEN ACCESS}

Edited by:

Karin Lykke-Hartmann,

Aarhus University, Denmark

Reviewed by:

Rajprasad Loganathan,

Johns Hopkins University,

United States

Andrew Burgess,

Anzac Research Institute, Australia

*Correspondence:

Ingrid Carvacho

icarvacho@ucm.cl;

ingridcarvacho@gmail.com

Specialty section

This article was submitted to

Cell Growth and Division

a section of the journal

Frontiers in Cell and Developmental

Biology

Received: 14 February 2018

Accepted: 04 June 2018

Published: 26 June 2018

Citation:

Carvacho I, Piesche M, Maier TJ and Machaca K (2018) Ion Channel

Function During Oocyte Maturation

and Fertilization.

Front. Cell Dev. Biol. 6:63.

doi: 10.3389/fcell.2018.00063
The proper maturation of both male and female gametes is essential for supporting fertilization and the early embryonic divisions. In the ovary, immature fully-grown oocytes that are arrested in prophase I of meiosis I are not able to support fertilization. Acquiring fertilization competence requires resumption of meiosis which encompasses the remodeling of multiple signaling pathways and the reorganization of cellular organelles. Collectively, this differentiation endows the egg with the ability to activate at fertilization and to promote the egg-to-embryo transition. Oocyte maturation is associated with changes in the electrical properties of the plasma membrane and alterations in the function and distribution of ion channels. Therefore, variations on the pattern of expression, distribution, and function of ion channels and transporters during oocyte maturation are fundamental to reproductive success. Ion channels and transporters are important in regulating membrane potential, but also in the case of calcium $\left(\mathrm{Ca}^{2+}\right)$, they play a critical role in modulating intracellular signaling pathways. In the context of fertilization, $\mathrm{Ca}^{2+}$ has been shown to be the universal activator of development at fertilization, playing a central role in early events associated with egg activation and the egg-to-embryo transition. These early events include the block of polyspermy, the completion of meiosis and the transition to the embryonic mitotic divisions. In this review, we discuss the role of ion channels during oocyte maturation, fertilization and early embryonic development. We will describe how ion channel studies in Xenopus oocytes, an extensively studied model of oocyte maturation, translate into a greater understanding of the role of ion channels in mammalian oocyte physiology.

Keywords: ion currents, fertilization, patch-clamp, membrane potential, oocyte maturation, $\mathrm{Ca}^{2+}$ signaling

\section{INTRODUCTION}

Historically, the studies of gamete maturation and fertilization have been intimately associated with the regulation of ionic currents in these cells. Some of the earliest discoveries in ion channel biology have been driven by the desire to understand the mechanisms governing fertilization. The calcium $\left(\mathrm{Ca}^{2+}\right)$-release theory of egg activation, which was conceived based on early experiments in the late 1920s and into the 1930s (Tyler, 1941) has withstood the test of time. Indeed, both single and repetitive $\mathrm{Ca}^{2+}$ transient(s), propagating as a $\mathrm{Ca}^{2+}$ release wave across the egg is recognized as the trigger for egg activation at fertilization in all species tested to date (Stricker, 1999; Machaca, 2007; Kashir et al., 2013). Further improvements in our understanding of the electrical properties of 
both oocyte and the egg, have shed light on important processes involved in fertilization including the block to polyspermy. Initial electrophysiology studies determined the essential role of plasma membrane (PM) depolarization to the establishment of a fast block to polyspermy in sea urchin and Xenopus oocytes, among other species (Jaffe, 1976; Cross and Elinson, 1980; Jaffe and Cross, 1984).

Oocyte maturation in vertebrates is initiated following the release of the extended meiotic arrest that vertebrate oocytes experience during their growth and development. Oocytes arrest at the prophase stage of meiosis I with the nuclear envelope still intact. During this stage, oocytes grow and accumulate macromolecular components required for fertilization and early embryonic development. Upon hormonal stimulation, oocytes exit this extended meiotic arrest and undergo a complex differentiation pathway that encompasses both a reductionist nuclear division (meiosis) and a comprehensive cytoplasmic reorganization. This prepares the oocyte for the egg-to-embryo transition following fertilization (Smith, 1989; Miyazaki, 1995; Hassold and Hunt, 2001). An important aspect of oocyte maturation is the remodeling of the $\mathrm{Ca}^{2+}$ signaling machinery to allow the egg to activate properly at fertilization (Machaca, 2007; Nader et al., 2013). The induction of oocyte maturation ultimately culminates through multiple steps in the activation of maturation promoting factor (MPF). MPF is composed of cyclin dependent kinase 1 (Cdk1), in complex with cyclin B (B-Cdk1), and the associated nuclear kinase Greatwall, also known as microtubule associate threonine like kinase (Gwl/MASTL). MPF is the master regulator of both meitotic and mitotic M-phase (Kishimoto, 2015). Oocyte maturation is complete when oocyte reaches a second arrest in metaphase of meiosis II at which stage they become fertilization-competent and are typically referred to as "eggs" (Smith, 1989; Bement and Capco, 1990). The arrest at metaphase II requires cytostatic factor (CSF) which inhibits the anaphase promoting complex (APC) and prevents progression to Anaphase II (Tunquist and Maller, 2003). The APC is an ubiquitin ligase that tags cyclin B and other regulatory proteins which results in the loss of Cdk1 activity triggering exit from metaphase arrest and allowing progression to anaphase (Schmidt et al., 2005; Inoue et al., 2007; Nishiyama et al., 2007). The activity of ion channels and transporters and their remodeling during oocyte maturation is ultimately governed by this complex signaling cascade. Therefore, oocyte maturation is a cellular differentiation program that prepares the egg for fertilization and for the egg-to-embryo transition processes where ionic conductances play essential roles.

In mammals, fertilization results in the release of a sperm specific phospholipase [phospholipase $\zeta$ (PLC $\zeta$ )] into the egg cytoplasm upon sperm-egg fusion. It has been proposed that PLC $\zeta$ hydrolyzes not only PM phosphoinositol 4,5 bisphosphate $\left(\mathrm{PIP}_{2}\right)$ but mainly intracellular $\mathrm{PIP}_{2}$ (Yu et al., 2012; Swann and Lai, 2016), generating inositol triphosphate $\left(\operatorname{Ins}_{3}\right)$ and diacylglycerol (DAG). InsP $\mathrm{P}_{3}$ binds to the $\mathrm{IP}_{3}$ receptor $\left(\mathrm{IP}_{3} \mathrm{R}\right)$ on the endoplasmic reticulum (ER) and triggers the release of $\mathrm{Ca}^{2+}$ which mediates egg activation (Saunders et al., 2002). The ultimate role of PLCS as the trigger for the $\mathrm{Ca}^{2+}$ oscillations in mammals was recently elucidated through the generation of a mice lacking Plczl $\left(P l c z 1^{-}\right)$. Wild type eggs that were injected with $\mathrm{Plcz1}^{-}$sperm were unable to mount $\mathrm{Ca}^{2+}$ oscillations. Similar results were observed in experiments of in-vitro fertilization (IVF) using $\mathrm{Plcz1}^{-}$sperm. Surprisingly, $P l c z 1^{-}$mice are fertile, yet they do exhibit subfertility phenotype, suggesting a redundant system for egg activation to assure reproduction in animals (Hachem et al., 2017). The fertilization $\mathrm{Ca}^{2+}$ signal takes the form of multiple oscillations that encode egg activation events, including pro-nucleus formation and the transition to embryonic development (Ducibella et al., 2002). In frogs, sea urchin and starfish, fertilization is also associated with a change of resting membrane potential, referred to as the "fertilization potential" which was compared to the action potential in neurons early on. The egg membrane potential undergoes a transient positive shift at fertilization that acts as an electrical polyspermy blockade. The effect of membrane potential depolarization on the polyspermy block was confirmed by holding the membrane potential of an unfertilized egg at positive potentials which prevented fertilization (Jaffe and Cross, 1984). In 2014, a detailed analysis of published data challenged the evidence of the fast block of polyspermy in sea urchin, proposing that a particular organization of the cytoskeleton could determine monospermic fertilization (Dale, 2014). However, the time scale of the electrical fast block would argue against it.

In contrast, hamster eggs showed transients hyperpolarization in response to fertilization (Miyazaki and Igusa, 1981), while mice eggs only showed very small hyperpolarization $(3-4 \mathrm{mV})$, questioning the existence of electrical block to polyspermy in this species (Igusa et al., 1983). It has rather been proposed that the block to polyspermy in mammals is based on the hardening of the zona pellucida ( $\mathrm{ZP})$. This process is mediated by the protein ovastacin whose function is to cleave zona pellucida 2 (ZP2), rendering the $\mathrm{ZP}$ resistance to protease digestion and inhibiting sperm binding (Burkart et al., 2012). Notwithstanding, transgenic mice containing a non-cleavable ZP2 and female mice null for ovastacin are both fertile, suggesting an additional mechanism or a combination of different strategies to avoid polyspermy (Bianchi and Wright, 2016).

In this review, we discuss the role of ionic currents at the PM primarily during oocyte maturation and fertilization. These conductances encompass transporters in addition to $\mathrm{Cl}^{-}$ channels, $\mathrm{K}^{+}$channels, $\mathrm{Ca}^{2+}$ channels, and other channels that are important in mediating fertilization and egg activation. Therefore, it is important to understand the regulation of these conductances as their remodeling contributes to define the competence of the egg to fertilization and undergo the eggto-embryo transition. Interestingly, the activity of ion channels during the processes of oocyte maturation and fertilization is not limited to channels localizing to the PM but also includes intracellular channels. As a case in point, the role of changes in the $\mathrm{IP}_{3}$ Receptor $\left(\mathrm{IP}_{3} \mathrm{R}\right)$ activity and localization observed during Xenopus oocyte maturation in preparing the egg for fertilization will be discussed.

The role that ionic currents play in the regulation of oocyte maturation is increasingly being recognized. Hence, it is important to elucidate the molecular mechanisms governing their remodeling during maturation and activity at fertilization. 
Furthermore, comparative studies from different species, as would be discussed herein between Xenopus and mammals, provide important insights into the mechanisms governing the regulation of ion channels in gametes.

\section{INITIAL MEASUREMENTS OF ION CHANNEL ACTIVITY IN REPRODUCTION}

The electrical properties of eggs particularly at fertilization have been of interest to embryologists since membrane potential changes were first recorded in neurons and muscle cells (Hille, 2001). It is now well established that the membrane potential is maintained by differences in ion concentrations between the intra and extra cellular media. The resulting generation of an electrical potential difference across the PM can be measured through electrophysiology. Intracellular voltage and current polarity are defined in relation to the "ground" (zero voltage) reference electrode in the extracellular medium (Ypey and DeFelice, 2000). Original assessments of the egg's membrane potential using standard electrophysiological approaches were performed in eggs from marine species. Although initial attempts using capillary microelectrodes failed, the implementation of intracellular microelectrodes allowed the measurement of resting potential and ion fluxes through the membrane of star fish eggs (Tyler et al., 1956). Invariably, the membrane potential in the resting state or "resting potential" (RP), in all living cells has a negative value expressed as a difference using the bath as the "ground" reference (for example, a neuron RP ranges from -70 to $-90 \mathrm{mV}$ ). Ion channels transport ions down their concentration gradient, from areas of high to low abundance, generating ion currents that determine, and regulate membrane potential (Hille, 2001; Tosti et al., 2013).

Using an intracellular microelectrode and a conventional extracellular ringer, the RP of mouse eggs was shown to vary depending on the mouse strain $(\sim-14$ to $-20 \mathrm{mV})$. The membrane showed permeability to $\mathrm{K}^{+}$and $\mathrm{Na}^{+}$, however, one needs to consider the possibility that these conductances may be affected by damage to the eggs by the electrode impalement procedure (Powers and Tupper, 1974; Hagiwara and Jaffe, 1979). The development of the patch-clamp technique changed the landscape relating to accuracy in data acquisition, allowing the mouse egg's RP and ion channel activity to be measured with minimal damage to the cell (Hamill et al., 1981). Conventional voltage-clamp and patch-clamp measurements indicate that in mouse eggs, the RP ranges between $\sim-30$ and $-50 \mathrm{mV}$ depending on the composition of the extracellular media (Igusa et al., 1983; Peres, 1986; Bernhardt et al., 2015). Using the same methodology, Maeno described a fundamental difference between the action potential of a nerve or muscle cell and the ones measured from oocytes and eggs from the toad. During egg activation, changes in membrane potential were caused by an increased permeability to $\mathrm{Cl}^{-}$ions, whereas action potentials of neurons and muscle cells were driven by changes in $\mathrm{Na}^{+}$ and $\mathrm{K}^{+}$conductances (Maeno, 1959). Electrophysiology is the most direct approach to study ion channels and allows direct characterization of these proteins in oocytes and eggs. Below, we describe the properties of ion channels that have been implicated in oocyte maturation and fertilization.

\section{XENOPUS VS. MAMMALIAN OOCYTES: COMPARISON OF ION CHANNEL EXPRESSION AND FUNCTION}

The fluxes of ions during oocyte maturation and at fertilization are mediated by ion channels, transporters and pumps. Most of them localize at the PM; however, intra and intercellular channels are also fundamental players supporting cellular processes. $\mathrm{Ca}^{2+}$ is the main signal underlying oocyte maturation and egg activation. Transport of $\mathrm{Ca}^{2+}$ through ion channels have been recognized as critical step, for example, to assure egg activation. In this section ion channels expressed in Xenopus and mammalian oocytes and eggs will be reviewed. Due to the fundamental role of $\mathrm{Ca}^{2+}$ in reproduction, we will focus on $\mathrm{Ca}^{2+}$ channels and $\mathrm{Ca}^{2+}$ modulated channels.

\section{$\mathrm{Ca}^{2+}$ Signaling}

$\mathrm{Ca}^{2+}$ is a universal second messenger that is fundamental to cellular signaling and homeostasis (Berridge, 2005; Clapham, 2007). The ionic nature of $\mathrm{Ca}^{2+}$ makes it unique among second messengers. Agonist activation of particular receptor types triggers the transport of $\mathrm{Ca}^{2+}$ into the signaling compartment (the cytoplasm) through channels, transporters and/or pumps. Cells support $\mathrm{Ca}^{2+}$ signaling by maintaining low cytoplasmic $\mathrm{Ca}^{2+}$ levels at rest $(\sim 100 \mathrm{nM})$. During the rising phase of a $\mathrm{Ca}^{2+}$ signal, $\mathrm{Ca}^{2+}$ flows into the cytoplasm either from the endoplasmic reticulum (ER) which concentrates $\mathrm{Ca}^{2+}$ at $250-600 \mu \mathrm{M}$, or from the extracellular space, where $\mathrm{Ca}^{2+}$ concentrations are typically 1-2 mM (Clapham, 1995; Demaurex and Frieden, 2003). ER localized non-selective cation channels, typically $\mathrm{IP}_{3}$ Receptors $\left(\mathrm{IP}_{3} \mathrm{R}\right)$ or Ryanodine Receptors (RyR), mediate $\mathrm{Ca}^{2+}$ release from the ER. Both $\mathrm{IP}_{3} \mathrm{Rs}$, and RyRs have been detected in rodent oocytes (Miyazaki et al., 1992; Kline and Kline, 1994). Xenopus oocytes, in contrast, express only a single isoform of $\mathrm{Ca}^{2+}$ release channels, the type $1 \mathrm{IP}_{3} \mathrm{R}$ (Parys et al., 1992; Parys and Bezprozvanny, 1995). Both mammals and Xenopus eggs require $\mathrm{IP}_{3}$-dependent $\mathrm{Ca}^{2+}$ release from the ER for egg activation at fertilization (Larabell and Nuccitelli, 1992; Miyazaki et al., 1992, 1993; Swann, 1992; Nuccitelli et al., 1993; Kline and Kline, 1994; Jones et al., 1995; Runft et al., 2002).

$\mathrm{Ca}^{2+}$ is the universal signal for egg activation at fertilization in all sexually reproducing species tested (Stricker, 1999; Whitaker, 2006). Thus, different species have evolved elaborate strategies to safeguard reproductive isolation. These include preventing the fusion of gametes from divergent species even if they are evolutionarily similar (Vieira and Miller, 2006). The versatility and diversity of $\mathrm{Ca}^{2+}$ in mediating a plethora of physiological responses make it an ideal second messenger to induce egg activation at fertilization. $\mathrm{Ca}^{2+}$ is able to signal across broad spatial (from the $\mathrm{nm}$ to $\mathrm{cm}$ scales) and temporal ( $\mu \mathrm{sec}$ to $\mathrm{h}$ ) ranges (Berridge et al., 2000). $\mathrm{Ca}^{2+}$ mediates cellular responses ranging from the rapid and localized like neurotransmitter 
release, to the slow and spatially spread out, such as the activation of development at fertilization.

Immature fully-grown vertebrate oocytes in the ovary are unable to support the egg-to-embryo transition. Eggs acquire the ability to be activated at fertilization during oocyte maturation. A major component of acquiring this competence is the remodeling of the $\mathrm{Ca}^{2+}$ signaling machinery, primarily the modulation of $\mathrm{Ca}^{2+}$ channels and transporters function during oocyte maturation. This has been best studied in Xenopus (Machaca, 2007) and mammalian oocytes, and will be reviewed briefly below.

\section{$\mathrm{Ca}^{2+}$ Release}

The frog egg is an exemplary model for the study of $\mathrm{Ca}^{2+}$ dependent egg activation processes including block to polyspermy and the release of metaphase II arrest to complete meiosis (Stricker, 1999; Runft et al., 2002; Whitaker, 2006). Immediately after sperm fusion, the $\mathrm{Ca}^{2+}$ transient activates $\mathrm{Ca}^{2+}$-activated $\mathrm{Cl}^{-}$channels (CaCC), resulting in membrane depolarization and the so called "fast electrical block to polyspermy" (Machaca et al., 2001). This is followed by cortical granule fusion which is also a $\mathrm{Ca}^{2+}$-dependent event. The cortical granule reaction results in modification of the egg extracellular matrix and a more permanent block to polyspermy (Grey et al., 1974; Wolf, 1974). Polyspermy block in mammals is hypothesized to occur through a similar $\mathrm{Ca}^{2+}$ evoked cortical granule release process (Abbott and Ducibella, 2001), in addition to other mechanisms.

Following the establishment of the polyspermy block, $\mathrm{Ca}^{2+}$ signaling then induces the egg to exit from metaphase II. The exit occurs by activating $\mathrm{Ca}^{2+}$-calmodulin-dependent protein kinase II (CaMKII) to start the egg activation processes (Lorca et al., 1993). CaMKII phosphorylates Emi2, an essential component of CSF (Schmidt et al., 2006). Emi2 is a direct inhibitor of APC. CaMKII-mediated degradation of Emi2 releases the oocyte from CSF-mediated metaphase II arrest, allowing anaphase II to proceed (Liu and Maller, 2005; Rauh et al., 2005; Tung et al., 2005). This activates the APC, leading to ubiquitination and degradation of Cyclin B. Degradation of Cyclin B, in turn, downregulates MPF activity and allows meiosis to reach completion (Morin et al., 1994). The fertilization-induced $\mathrm{Ca}^{2+}$ signal also activates the $\mathrm{Ca}^{2+}$-dependent phosphatase, calcineurin, which reinforces APC activation and the degradation of Cyclin B (Mochida and Hunt, 2007; Nishiyama et al., 2007). $\mathrm{The} \mathrm{Ca}^{2+}$ transient induced by fertilization encodes sequential cellular rearrangements that are critical for egg activation.

\section{$\mathrm{IP}_{\mathbf{3}}$ Receptor}

$\mathrm{IP}_{3}$ receptors $\left(\mathrm{IP}_{3} \mathrm{R}\right)$ are tetrameric channels with the structure of each subunit consisting of six transmembrane domains, a p-loop and a large cytoplasmic domain representing the bulk of the protein. They are non-selective cation channels that are $\mathrm{Ca}^{2+}$-permeant. Given the large $\mathrm{Ca}^{2+}$ gradient established across the ER membrane, $\mathrm{IP}_{3} \mathrm{R}$ gating results in $\mathrm{Ca}^{2+}$ release from intracellular ER $\mathrm{Ca}^{2+}$ stores (Parys and Bezprozvanny, 1995; Foskett et al., 2007). The $\mathrm{IP}_{3} \mathrm{R}$ has three isoforms, type 1,2 , and 3. All three isoforms are expressed in mammalian oocytes and eggs, with the type I isoform being the most dominant (Wakai et al., 2011). The $\mathrm{IP}_{3} \mathrm{R}$ is modulated by $\mathrm{Ca}^{2+}$ and $\mathrm{IP}_{3}$ and requires the binding of both for the conduction path to open (Taylor and Tovey, 2010). In most vertebrates, the $\mathrm{IP}_{3} \mathrm{R}$ is responsible for the fertilization-induced $\mathrm{Ca}^{2+}$ transient. In mammals, an initial first large $\mathrm{Ca}^{2+}$ transient is observed upon fertilization, similar to event observed in frog eggs. Unique to mammals however, are the multiple $\mathrm{Ca}^{2+}$ oscillations that follow this large transient, and last for several hours (Kline and Kline, 1992; Mohri et al., 2001). The phosphorylation of the $\mathrm{IP}_{3} \mathrm{R}$ was proposed to modulate $\mathrm{Ca}^{2+}$ fluxes from the ER. Initial theories proposed that phosphorylation impacted the activity of the $\mathrm{IP}_{3} \mathrm{R}$ during oocyte maturation by promoting $\mathrm{Ca}^{2+}$ transport at fertilization (Fujiwara et al., 1993; Mehlmann and Kline, 1994; Terasaki et al., 2001; Machaca, 2004; Zhang et al., 2015); (Table 1). In mouse $\mathrm{IP}_{3} \mathrm{R}$, several serine/threonine residues have been identified as targets for phosphorylation during oocyte maturation (Westendorf et al., 1994). Cell cycle kinases such as mitogen-activated protein kinase (MAPK), extracellular signal-regulated kinase (ERK) and Cdk1 have been shown to phosphorylate the receptor (Bai et al., 2006; Lee et al., 2006; Zhang et al., 2015). Kinase motifs include the Cdk1 consensus sites $\left[S^{421}, \mathrm{~T}^{799}, \mathrm{~S}^{2147}\right]$ (Nigg, 1991; Malathi et al., 2003; Wakai et al., 2012) and the ERK site [S ${ }^{436}$ ] (Bai et al., 2006; Lee et al., 2006). In addition, several other kinases have been reported to phosphorylate the $\mathrm{IP}_{3} \mathrm{R}$ including protein kinase A (PKA, $\left[\mathrm{S}^{1589}\right.$, $\mathrm{S}^{1755}$, and $\mathrm{T}^{930}$ ] Ferris et al., 1991; Haun et al., 2012; Xu and Yang, 2017), protein kinase $\mathrm{G}$ (PKG, same sites as PKA), protein kinase C (PKC, Vanderheyden et al., 2009) and protein kinase B (PKB or Akt, [ $\left.{ }^{2681}\right]$ Vanderheyden et al., 2009. Other kinases such as CaMKII and Rho kinases also mediate phosphorylation of the $\mathrm{IP}_{3} \mathrm{R}$ (Vanderheyden et al., 2009). Originally, it was suggested that phosphorylation modulates the function of the $\mathrm{IP}_{3} \mathrm{R}$ by sensitizing its release of $\mathrm{Ca}^{2+}$ at fertilization (Fujiwara et al., 1993; Mehlmann and Kline, 1994; Terasaki et al., 2001; Machaca, 2004; Zhang et al., 2015) (Table 1). In Xenopus, this sensitization was thought to be due to an increased affinity of the $\mathrm{IP}_{3} \mathrm{R}$ for $\mathrm{IP}_{3}$ (Machaca, 2004; Ullah et al., 2007). However, phosphorylation of the $\mathrm{IP}_{3} \mathrm{R}$ does not ultimately result in an increased affinity for $\mathrm{IP}_{3}$ (Sun et al., 2009). High constitutive PKA activity in the oocyte is required to maintain meiotic arrest, resulting in basal phosphorylation of $\mathrm{IP}_{3} \mathrm{R}$ PKA sites. This phosphorylation is unaltered during maturation (Sun et al., 2009). The $\mathrm{IP}_{3} \mathrm{R}$ is also phosphorylated at additional sites that match the MAPK and/or the Cdk1. Activation of MAPK or Cdk1 is required for sensitizing $\mathrm{IP}_{3}$-dependent $\mathrm{Ca}^{2+}$ release during oocyte maturation (Sun et al., 2009). The MAPK/Cdk1 consensus phosphorylation sites altered during oocyte maturation are T931, T1136, and T1145 (Sun et al., 2009). Surprisingly though, phosphorylation of the $\mathrm{IP}_{3} \mathrm{R}$ on at least one of those residues decreased its affinity to $\mathrm{IP}_{3}$ rather than the expected increase in affinity (Haun et al., 2012). This observation argues against phosphorylation being the primary driver of the increased sensitivity of the $\mathrm{IP}_{3} \mathrm{R}$ for $\mathrm{IP}_{3}$ observed during maturation. As it turns out, the mechanism is much more complex and elegant. The ER suffers dramatic remodeling that is dependent on the kinase cascades activated during maturation, in the process of "geometric sensitization" (Sun et al., 2011). 
TABLE 1 | Channel expression and function in Xenopus and mouse oocytes and eggs.

\begin{tabular}{|c|c|c|}
\hline Channel & Xenopus & Mouse \\
\hline \multicolumn{3}{|l|}{ INTRACELLULAR } \\
\hline $\mathrm{IP}_{3} \mathrm{R} 1$ & $\begin{array}{l}\text { Oocytes and eggs showed responses to } I_{3} . I_{3} R \text { in mature } \\
\text { eggs is more sensitive to } I_{3} \text { than it is in oocytes (Terasaki } \\
\text { et al., 2001; Machaca, 2004; Sun et al., 2009, 2011) }\end{array}$ & $\begin{array}{l}\text { Expressed at GV oocytes and MII eggs. Increases activity } \\
\text { during oocyte maturation (Mehlmann and Kline, 1994) }\end{array}$ \\
\hline \multicolumn{3}{|l|}{ PLASMA MEMBRANE (PM) } \\
\hline CRAC (ORAI+STIM) & $\begin{array}{l}\text { Inactivates during oocyte maturation (Machaca and Haun, } \\
\text { 2000, 2002; Yu et al., 2009, 2010) }\end{array}$ & $\begin{array}{l}\text { Inactivates during oocyte maturation (Cheon et al., 2013; } \\
\text { Lee et al., 2013). Orai and Stim KO animals are fertile } \\
\text { (Bernhardt et al., 2017) }\end{array}$ \\
\hline T type $\mathrm{Ca}^{2+}$ channel & Not reported & $\begin{array}{l}\text { Expressed in GV and MII. KO animals are fertile (Chen } \\
\text { et al., 2003; Bernhardt et al., 2015) }\end{array}$ \\
\hline TRPV3 & Not reported & $\begin{array}{l}\text { Expressed at Ml oocytes and MIl eggs. KO animals are } \\
\text { fertile (Cheng et al., 2010; Carvacho et al., 2013) }\end{array}$ \\
\hline TRPM7 & Not reported & $\begin{array}{l}\text { TRPM7-like currents are expressed at GV, MII and in } \\
\text { 2-cell embryos (Carvacho et al., 2016) }\end{array}$ \\
\hline Swell-activated $\mathrm{Cl}^{-}$channels & Not reported & $\begin{array}{l}\text { Functionally expressed in Mll eggs and embryos } \\
\text { (Kolajova et al., 2001) }\end{array}$ \\
\hline Voltage activated $\mathrm{K}^{+}$channels & Expressed in eggs (Tokimasa and North, 1996) & Reported in MIl eggs (Day et al., 1993) \\
\hline Connexins (Cx37 and $\mathrm{C} \times 43)$ & Not reported & $\begin{array}{l}\text { Cx37 KO animals are infertile (Simon et al., 1997) } \\
\text { Ovaries lacking Cx43 contain oocytes that cannot be } \\
\text { fertilized (Ackert et al., 2001) }\end{array}$ \\
\hline
\end{tabular}

The ER remodeling results in the formation of large patches of convoluted membranes highly enriched with $\mathrm{IP}_{3} \mathrm{Rs}$ orienting in close apposition to each other (Sun et al., 2011). IP 3 Rs within these ER patches exhibit a significantly enhanced sensitivity to $\mathrm{IP}_{3}$ compared to $\mathrm{IP}_{3} \mathrm{Rs}$ within the adjacent ER, despite the fact that $\mathrm{IP}_{3}$ Rs exchange freely between the patches and adjacent ER (Sun et al., 2011). Thus, the sensitization of $\mathrm{IP}_{3} \mathrm{Rs}$ during oocyte maturation is due to ER remodeling, and the enhanced $\mathrm{Ca}^{2+}$. induced $\mathrm{Ca}^{2+}$ release evoked by the close apposition of $\mathrm{IP}_{3} \mathrm{Rs}$ (geometric sensitization) (Sun et al., 2011).

Another $\mathrm{Ca}^{2+}$ transport protein, the $\mathrm{PM} \mathrm{Ca}{ }^{2+}$-ATPase (PMCA), is also modulated during oocyte maturation. In Xenopus oocytes, PMCA localizes to the PM where it contributes to $\mathrm{Ca}^{2+}$ extrusion. This activity supports the return of cytoplasmic $\mathrm{Ca}^{2+}$ concentration to baseline levels following a $\mathrm{Ca}^{2+}$ transient at fertilization (El Jouni et al., 2005, 2008). During oocyte maturation, the PMCA is removed from the PM through an internalization process that places them in an intracellular vesicular pool (El Jouni et al., 2005, 2008). PMCA internalization during meiosis is dependent on its N-terminal cytoplasmic domain and on MPF activation (El Jouni et al., 2008). Furthermore, several lines of evidence argue that PMCA internalization goes through a lipid-raft endocytic pathway (El Jouni et al., 2008).

\section{Calcium Channels}

\section{Store-Operated $\mathrm{Ca}^{2+}$ Entry, SOCE}

$\mathrm{Ca}^{2+}$ influx into cells is mediated by a diverse population of $\mathrm{Ca}^{2+}$ transport proteins exhibiting significant diversity in their gating and activation mechanisms. $\mathrm{Ca}^{2+}$ channels at the $\mathrm{PM}$ can be gated by voltage, ligand, second messengers, store depletion, or physically through protein-protein interactions. In vertebrate oocytes the predominant $\mathrm{Ca}^{2+}$ influx pathway appears to be through store-operated $\mathrm{Ca}^{2+}$ entry (SOCE). SOCE is directly regulated by the level of $\mathrm{Ca}^{2+}$ in intracellular ER stores (Kline and Kline, 1992; Hartzell, 1996; Machaca and Haun, 2000, 2002). Emptying of intracellular ER stores can be triggered using thapsigargin, an irreversible inhibitor of the sarcoplasmic reticulum/ER Ca-ATPase (SERCA). The pathway through which $\mathrm{Ca}^{2+}$ exits the ER into the cytoplasm following thapsigargin treatment has not yet been identified. Thapsigargin-induced depletion of the ER $\mathrm{Ca}^{2+}$ store activates the influx of extracellular $\mathrm{Ca}^{2+}$ into the cytoplasm of unfertilized eggs (Kline and Kline, 1992). When ER $\mathrm{Ca}^{2+}$ stores have been significantly depleted by the persistent presence of thapsigargin, sperm are no longer capable of triggering $\mathrm{Ca}^{2+}$ oscillations (Kline and Kline, 1992). Evidence that $\mathrm{Ca}^{2+}$ influx is essential for the maintenance of oscillations triggered by sperm was demonstrated by addition of BAPTA to the extracellular media. BAPTA is a membrane impermeable $\mathrm{Ca}^{2+}$ chelator which prevented the generation of oscillations by the sperm (Kline and Kline, 1992). Additionally, the frequency of $\mathrm{Ca}^{2+}$ oscillations can be modulated by changing the external concentration of $\mathrm{Ca}^{2+}$ (Shiina et al., 1993). Thus, extracellular $\mathrm{Ca}^{2+}$ is an important source to support $\mathrm{Ca}^{2+}$ oscillations.

SOCE or $\mathrm{Ca}^{2+}$ release-activated $\mathrm{Ca}^{2+}$ channels (CRAC), were first described in immune cells where they have been shown to be critical for their activation. Accordingly, defects in SOCE in 
humans are associated with severe immunodeficiencies (Bogeski et al., 2010). SOCE is mediated through the interactions of ER $\mathrm{Ca}^{2+}$ sensors, stromal interaction molecule (STIM), with ORAI ion channels at the PM. STIM proteins cluster in the ER following store depletion, localizing to ER-PM junctions where they physically recruit and interact with ORAI proteins to gate their pore open (Lewis, 1999). ORAIs are 4 pass transmembrane proteins that form highly $\mathrm{Ca}^{2+}$-selective channels (Prakriya et al., 2006; Vig et al., 2006). STIM has two homologs: STIM 1 and 2; and ORAI has three family members, ORAI1, 2 and 3 (Shim et al., 2015).

During Xenopus oocyte maturation, SOCE is completely inactivated (Machaca and Haun, 2000). This inactivation is essential for the remodeling of $\mathrm{Ca}^{2+}$ signaling pathways to enable the generation of the specialized fertilization-specific $\mathrm{Ca}^{2+}$ transient that encodes the egg-to-embryo transition (Machaca, 2007; Nader et al., 2013) (Table 1). As discussed above, this $\mathrm{Ca}^{2+}$ signal at fertilization is the spark that induces egg activation (Fontanilla and Nuccitelli, 1998). Xenopus oocyte SOCE downregulation may represent a safety mechanism to prevent premature activation due to spontaneous $\mathrm{Ca}^{2+}$ influx. Xenopus eggs are ovulated in pond water of uncontrolled ionic content. Indeed, all ionic currents across the egg PM tend to be downregulated, with the exception of the $\mathrm{Ca}^{2+}$-activated $\mathrm{Cl}$ channels which are required for the block to polyspermy as discussed below (Nader et al., 2013).

The mechanisms governing SOCE inhibition during Xenopus oocyte maturation have been studied in detail. The activation of MPF is required for SOCE inhibition during maturation (Machaca and Haun, 2002). This results in the internalization of ORAI1 into a Rab5-positive endosomal compartment through a caveolin and dynamin-dependent endocytic pathway (Yu et al., 2009, 2010). STIM1 does maintain its ability to interact with ORAI1 in Xenopus eggs, however, in mature eggs; ER store depletion does not lead to STIM1 clustering. Clustering is a pre-requisite for STIM stabilization in the cortical ER (Yu et al., 2009). Although stim1 is phosphorylated during oocyte maturation, this phosphorylation does not modulate STIM1 function or its inhibition during meiosis. Mutant STIM proteins that cannot be phosphorylated are unable to rescue SOCE downregulation in Xenopus eggs, even when co-expressed with an Orail mutant that cannot be internalized (Yu et al., 2009; 2010).

Expression of SOCE components in mammals has been shown at the mRNA levels as well as by immunocytochemistry and western blotting in mouse oocytes (Gomez-Fernandez et al., 2009; Cheon et al., 2013) and porcine eggs (Koh et al., 2009; Wang et al., 2012). However, in some cases, the specificity of the antibodies used requires additional confirmation. Further, the function of SOCE during mouse fertilization remains controversial and may play a minor role. In a MII egg study, STIM1 was found to form discrete patches co-localizing with an ER marker prior to fertilization. This organization changed following $\mathrm{Ca}^{2+}$ depletion showing high co-localization with ORAI1. Thus, a role for SOCE in $\mathrm{Ca}^{2+}$ signaling during fertilization was suggested (Gomez-Fernandez et al., 2009, 2012). However, the size of the large STIM patches observed in these studies was not consistent with the patch size noted in other cells. In addition, specific inhibitors of SOCE did not disrupt $\mathrm{Ca}^{2+}$ oscillations induced by fertilization (Miao et al., 2012; Carvacho et al., 2013). Finally, experiments tracking the expression of exogenously-tagged STIM1 and ORAI1 proteins found that SOCE downregulation during oocyte maturation was mainly due to reorganization of STIM and an internalization of ORAI1 (Cheon et al., 2013; Lee et al., 2013) (Table 1 and Figure 1).

One of the main issues regarding the functional expression of CRAC channels in mouse eggs is the lack of electrophysiological evidence. CRAC channels have a small unitary conductance such that at physiological concentration of $\mathrm{Ca}^{2+}(2 \mathrm{mM})$ the single channel conductance of CRAC channels is $\leq 9 \mathrm{fS}$, and at $20 \mathrm{mM} \mathrm{Ca}^{2+}$ it is $18-24 \mathrm{fS}$ (McNally and Prakriya, 2012). Given the magnitude of the expected whole-cell current and

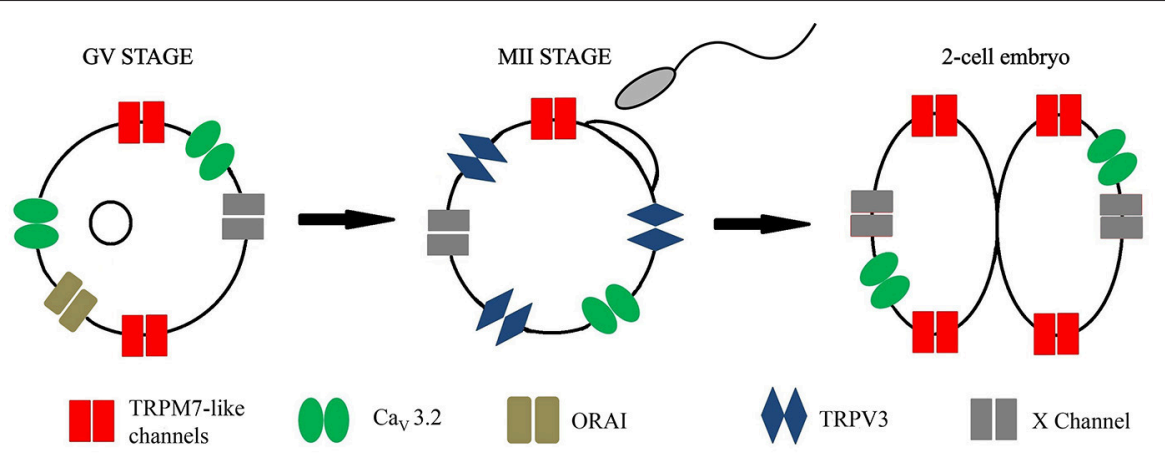

$\mathrm{Ca}_{\mathrm{V}} 3.2$ :
- Contributes to $\mathrm{ER} \mathrm{Ca}^{2+}$ accumulation
during maturation.
TRPM7-like channels:
- Mediate $\mathrm{Ca}^{2+}$ oscillations?
ORAI: ?

$\mathrm{Ca}_{\mathrm{V}} 3.2$

- Might contribute to $\mathrm{Ca}^{2+}$ oscillations? TRPV3:

- Mediates $\mathrm{Ca}^{2+}$ influx

TRPM7- like channels:

- Contributes to $\mathrm{Ca}^{2+}$ influx?
TRPM7-like channels:

- Support pre-implantation embryo

development?.

FIGURE 1 | Schematic representation of the $\mathrm{Ca}^{2+}$ channels reported to be expressed in GV stage, MII, and 2-cell embryo. GV, germinal vesicle. 
the background currents in eggs, detection of CRAC channels activity would be technically challenging. Additionally, protocols to empty intracellular $\mathrm{Ca}^{2+}$ stores weaken the stability of the patch-clamp seal during electrophysiological measurements. Final confirmation that the function of STIM1 and ORAI1 are not required for fertilization and the egg-to-embryo transition came from the generation of oocyte-specific knockout mouse line for Stim1/2 and the study of the global KO for Orail (Vig et al., 2008). These lines showed no fertility defects and the eggs showed a normal pattern of $\mathrm{Ca}^{2+}$ oscillations at fertilization (Bernhardt et al., 2017).

There are reports that SOCE in some cell types can be mediated by interaction between STIM1 and members of the Transient Receptor Potential (TRP) channel family, particularly from the TRP canonical (TRPC) subfamily (Zeng et al., 2008; Yuan et al., 2009). TRPCs channels have been proposed to interact with STIM1 and act as store-operated channels. TRPC can form complexes with ORAI, however, it has been shown that ORAI channels are functional in absence of TRPCs (Birnbaumer, 2015). Additionally, the heptaKO females for TRPCs (C1-C7) channels are fertile (Birnbaumer, 2015) and eggs from these animals showed normal $\mathrm{Ca}^{2+}$ oscillations (Bernhardt et al., 2017). These evidences rule out a role for TRPCs in $\mathrm{Ca}^{2+}$ influx. The fact that a Stim 1/2 KO mouse is fertile argues that SOCE is not essential for fertilization in this species or that there are redundant ionic pathways in the eggs able to refill the stores sufficiently even in the absence of SOCE. The latter scenario seems more attractive especially that SOCE is detectable by $\mathrm{Ca}^{2+}$ imaging in mouse eggs despite the fact that it is downregulated during oocyte maturation (Cheon et al., 2013; Lee et al., 2013). Despite the strong evidence against a role for STIM and ORAI at fertilization, their overexpression in mouse oocyte has been shown to disrupt early embryonic development (Lee et al., 2013). Thus, the regulation of $\mathrm{Ca}^{2+}$ influx during fertilization is critical for normal egg-to-embryo transition.

In pig eggs, the evidence that STIM1 plays a role in refilling intracellular $\mathrm{Ca}^{2+}$ stores and fertilization is more direct: knockdown of Stim1, using RNAi, abolished thapsigargininduced $\mathrm{Ca}^{2+}$ influx (Koh et al., 2009), sperm-induced $\mathrm{Ca}^{2+}$ oscillations and affected embryo development (Lee et al., 2012). Manipulating the expression of Orail also had consequences on store-operated $\mathrm{Ca}^{2+}$ influx. Overexpression of Orail disrupted the oscillations triggered by fertilization. Downregulation of Orail abolished $\mathrm{Ca}^{2+}$ oscillations and diminished the rate of blastocyst formation (Wang et al., 2012; Machaty et al., 2017). Using FRET (Fluorescence Resonance Energy Transfer) it was shown that mVenus-Stim 1 and mTurquoise2-Orai, constructs that were injected in eggs, interacted following a cyclic pattern in response to store depletion during sperm-induced $\mathrm{Ca}^{2+}$ oscillations (Zhang et al., 2018). This interaction suggests a role for SOCE during fertilization in pigs. Overexpression of proteins that accumulate at the PM or in its vicinity can cause non-specific effects on the function of channels. Therefore, electrophysiological detection of native CRAC current in these eggs will be necessary to confirm its functional expression and clarify its role in the early stage of development.

\section{Voltage Gated $\mathrm{Ca}^{2+}$ Channels, $\mathrm{Ca}_{v}$ Channels}

Voltage-gated $\mathrm{Ca}^{2+}(\mathrm{Ca})$ channels are transmembrane proteins that are organized in four domains (I-IV) with each domain having six transmembrane segments (S1-S6). $\mathrm{Ca}_{V}$ channels can be classified into two groups according to the voltage changes required for activation: high-voltage activated (HVA) channels and low-voltage activated (LVA). $\mathrm{Ca}_{\mathrm{v}}$ 1.1-1.4 (L-type current) and $\mathrm{Ca}_{\mathrm{v}} 2.1-2.3$ (P/Q, N, and $\mathrm{R}$ type) belong to the HVA group, while $\mathrm{Ca}_{\mathrm{v}} 3.1-3.3$ (Ttype current) to the LVA group. Between other functions, voltage-gated $\mathrm{Ca}^{2+}$ channels are responsible for initiation of synaptic transmission, hormone secretion, and excitationcontraction coupling (Hille, 2001; Catterall, 2011; Ramirez et al., 2017).

In 1977, using the voltage-clamp technique, an inward $\mathrm{Ca}^{2+}$ current was described in mouse eggs. The recordings were done in $20 \mathrm{mM}$ external $\mathrm{Ca}^{2+}$ and the inward current increased in response to depolarizing steps. The peak current was measured at $\sim-15 \mathrm{mV}$ and it showed a dramatic reduction at temperatures below $20^{\circ}$ C. Replacement of external $\mathrm{Ca}^{2+}$ by $\mathrm{Sr}^{2+}$ or $\mathrm{Ba}^{2+}$ retained the biophysical characteristics of the channel. Sea urchin and tunicate eggs also showed an inward $\mathrm{Ca}^{2+}$ current but with different inactivation time and permeability ratio than the one recorded in mouse eggs (Okamoto et al., 1977). In mouse eggs, using an improved set-up, the maximal current was at $\sim-30 \mathrm{mV}$ and its reversal potential was $\sim+50 \mathrm{mV}$ (Peres, 1987). Similar characteristics were found using the patch-clamp technique (Kang et al., 2007; Bernhardt et al., 2015). Additional recordings of mouse ovarian oocytes using single-glass microelectrodes showed inward currents carried by monovalent cations. These currents were blocked by $\mathrm{Ca}^{2+}$ channel antagonists and were insensitive to tetrodotoxin (TTX), confirming the functional presence of $\mathrm{Ca}^{2+}$ channels before ovulation (Yoshida, 1983). After fertilization, the voltage-gated $\mathrm{Ca}^{2+}$ channel varies in magnitude but not in kinetics or selectivity (Yamashita, 1982; Day et al., 1998; Kang et al., 2007). Voltage-gated $\mathrm{Ca}^{2+}$ channels were also described in hamster (Georgiou et al., 1984) and bovine eggs (Tosti et al., 2000). Comparable voltage-gated channels were recorded in ascidians and mollusks (Gallo et al., 2013; Tosti et al., 2013). Later, biophysical characterizations of the $\mathrm{Ca}_{\mathrm{V}}$ current in mouse eggs assigned it molecularly as a T-type 3.2, voltage-gated $\mathrm{Ca}^{2+}$ channel (Kang et al., 2007) (Table 1). Surprisingly, even when the T-type current is prominent in mouse eggs (peak reaches $\sim 1.5 \mathrm{nA}$ in MII eggs, in $2 \mathrm{mM} \mathrm{Ca}^{2+}$ ), mice null for this channel, Cacnalh-/- (Chen et al., 2003), showed only marginal subfertility (Bernhardt et al., 2015). These results suggest that the function of this channel may be to support $\mathrm{Ca}^{2+}$ influx during the germinal vesicle arrest (GV; Figure 1) and during maturation. $\mathrm{Ca}_{V}$ channels would then contribute to fill the intracellular ER $\mathrm{Ca}^{2+}$ stores (Figure 1) and maintain $\mathrm{Ca}^{2+}$ homeostasis in preparation for fertilization (Bernhardt et al., 2015).

Native $\mathrm{Ca}_{\mathrm{V}}$ channels of an unspecified type are expressed in Xenopus oocyte. The conductance was smaller than most conductances recorded in these cells (Dascal et al., 1986). Their function remains unknown. 


\section{Transient Receptor Potential (TRP) Channels}

The TRP channels are a family of cationic non-selective channels that are known as cellular sensors. TRP channels are modulated by common second messengers such as $\mathrm{PIP}_{2}$ and intracellular $\mathrm{Ca}^{2+}$ but also respond to more general stimuli such as temperature, $\mathrm{pH}$ and osmolarity, among others. TRP channels are tetramers where each subunit includes six transmembrane domains (S1-S6) and a p-loop that defines the channel pore (Wu et al., 2010).

TRP channels expression in mouse eggs have been recently validated, despite the fact that a temperature-dependent, outward current was reported in mouse eggs nearly 40 years ago (Okamoto et al., 1977). Confirmation of expression and function of TRP channels in mature eggs was accomplished using patchclamp and $\mathrm{Ca}^{2+}$ imaging (Carvacho et al., 2013). The first TRP channel reported in eggs was TRPV3 channel. TRPV3 is a member of the vanilloid subfamily of the TRP family which is highly expressed in skin. TRPV3 is activated by stimuli such as temperature and plant-derivatives compounds (e.g., carvacrol and eugenol). Other traditional $\mathrm{Ca}^{2+}$ channel blockers such as 2-aminoethoxydiphenyl borate (2-APB) are also modulators of TRPV3 (Peier et al., 2002; Smith et al., 2002; Xu et al., 2002; $\mathrm{Hu}$ et al., 2004; Lee et al., 2016). TRPV3, similar to many other members of the TRP family can act downstream of Gprotein coupled receptor activation (Yang and Zhu, 2014). In mouse eggs a combination of electrophysiological recording and using the agonist 2-APB showed that TRPV3 current is detectable in WT eggs but not in those from TprV3 $3^{-/-}$animals (Carvacho et al., 2013). The current developed progressively during oocyte maturation, reaching the highest level in eggs at the MII stage. TRPV3 can mediate $\mathrm{Ca}^{2+}$ influx (Figure 1) which causes an intracellular $\mathrm{Ca}^{2+}$ rise capable of promoting parthenogenesis in ovulated eggs. Parthenogenesis and $\mathrm{Ca}^{2+}$ oscillations can be triggered artificially by incubation of the ovulated eggs in a strontium-containing media (Whittingham and Siracusa, 1978). TRPV3 channels are responsible for the influx of strontium $\left(\mathrm{Sr}^{2+}\right)$ into eggs. Incubation of mouse eggs in $\mathrm{Sr}^{2+}$ containing media has been used for years to induce artificial activation. $\mathrm{Sr}^{2+}$-induced egg activation is a procedure that is widely used for animal cloning (Wakayama et al., 1998). Despite the expression of TRPV3 current in MII eggs, $\operatorname{Tr} p V 3^{-/-}$ females are fertile (Cheng et al., 2010; Carvacho et al., 2013). These studies suggest the function of an additional channel mediating $\mathrm{Ca}^{2+}$ influx, or as discussed above, the concerted function of multiple redundant pathways to ensure proper egg activation. Consistently, a recent study showed the presence of the TrpV3 transcript in human oocytes. The TRPV3 agonists 2 -APB and carvacrol were shown to promote egg activation suggesting functional expression of channels, despite the fact that $\mathrm{Sr}^{2+}$ fails to induce activation in human eggs ( $\mathrm{Lu}$ et al., 2018). One explanation to these results could be that human TRPV3 channels display a different sequence of ion selectivity than mouse TRPV3. Alternatively, the level of localization of TRPV3 at the PM could be too low to allow sufficient $\mathrm{Sr}^{2+}$ to induce intracellular $\mathrm{Ca}^{2+}$ release. Direct assessments of functional expression of TRPV3 channels in human oocytes would help to solve differences between mouse and human eggs.

Recently, another member of the TRP channels family, TRPM7, was found to be expressed in mouse eggs. TRPM7 belongs to the subfamily of melastatin and exhibits a ubiquitous tissue distribution. Trpm $7^{-/-}$global knock-out is embryonic lethal. Embryos Trpm $7^{f l f l}$ (Cre-ER) derived from a tamoxifeninducible (Cre-ER) transgenic line bred to $\operatorname{Trp} m 7^{f l / f l}$ died earlier than E14.5 (Jin et al., 2008, 2012). One possible interpretation of these results is that TRPM7 is expressed in eggs and/or embryos. Accordingly, a monovalent cationic outward current with the characteristics of a TRP channel was recorded in mouse TRPV3 KO eggs using whole cell patch clamp. The channel responds to TRPM7 agonists and blockers. TRPM7like current was also detected in 2-cell stage embryos (Table 1 and Figure 1). The chemical suppression of the channel hours after fertilization reduced progression to the blastocyst stage, in agreement with a possible role of TRPM7 in pre-implantation embryo development (Carvacho et al., 2016). Using the same blocker (NS8593), Williams's group showed that eggs treated with NS8593 and fertilized in-vitro display impaired $\mathrm{Ca}^{2+}$ oscillations (Bernhardt et al., 2017). Future studies following the generation of an oocyte-specific KO for TRPM7 will provide more specific answers about the contribution of TRPM7 during fertilization and/or pre-implantation embryo development.

Expression of TRP channels have been reported in Xenopus oocytes. In contrast to mouse oocytes, Xenopus TRP channels seem to be inactive. TRPC1 protein was detected by western blot and immunolocalization, and it was suggested to underlie SOCE in Xenopus oocytes (Bobanovic et al., 1999). However, the function of the TRPC1 protein as channel is debatable (Wu et al., 2010). Using RT-PCR and western blot, a Xenopus homolog of TRPV5/6, xTRPV6, was found in Xenopus oocytes (Courjaret et al., 2013). xTRPV6 channel is not active at PM, although it has been suggested that its functional expression is modulated by interacting with TRPC1 (Schindl et al., 2012; Courjaret et al., 2013).

\section{Chloride Channels $\mathrm{Ca}^{2+}$-Activated $\mathrm{Cl}^{-}$Channels}

The Xenopus egg is $\sim 1.2 \mathrm{~mm}$ in diameter allowing ample membrane area for sperm entry. The slow fusion of cortical granules induced by the fertilization-specific $\mathrm{Ca}^{2+}$ signal and the time required for the released enzymes to modify the egg extracellular matrix are too long to prevent additional sperm from entering the egg after the first sperm-egg fusion event. Therefore, Xenopus eggs have evolved a fast electrical block to polyspermy that is dependent on the $\mathrm{Ca}^{2+}$-dependent gating of $\mathrm{Ca}^{2+}$-activated $\mathrm{Cl}^{-}$channels (CaCC) (Table 1). CaCC depolarize the cell membrane thus preventing additional sperm from fusing with the egg (Cross and Elinson, 1980; Jaffe et al., 1983). Interestingly, early studies have shown that simply incubating eggs in media with high $\mathrm{Cl}^{-}$or replacing $\mathrm{Cl}^{-}$with other anions such as $\mathrm{I}^{-}$or $\mathrm{Br}^{-}$lead to polyspermy (Bataillon, 1919; Grey et al., 1982). In retrospect, the effects of these ion substitutions on polyspermy are expected. CaCC induces 
membrane depolarization by conducting $\mathrm{Cl}^{-}$out of the cell, thus a high extracellular $\mathrm{Cl}^{-}$will inhibit $\mathrm{Cl}^{-}$efflux and membrane depolarization, promoting polyspermy.

CaCC-mediated currents are the predominant currents in Xenopus oocytes and are required to maintain the oocyte resting membrane potential (Kuruma and Hartzell, 2000). CaCC are encoded by TMEM16A also known as Anoctamin 1 or Ano1 (Schroeder et al., 2008; Yang et al., 2008). In Xenopus oocytes, CaCC interact with ERM proteins to regulate the length of microvilli and the membrane surface area (Courjaret et al., 2016; Table 1). CaCC are activated in response to the sperm-induced $\mathrm{Ca}^{2+}$ release at fertilization. CaCC activation and membrane depolarization can be replicated in the egg using different $\mathrm{Ca}^{2+}$ sources. Functional assays include pricking the egg and injecting $\mathrm{Ca}^{2+}$ or $\mathrm{IP}_{3}$ directly on the egg. Another alternative is treating the egg with $\mathrm{Ca}^{2+}$ ionophores (Wolf, 1974; Cross, 1981; Busa et al., 1985; Machaca et al., 2001).

$\mathrm{CaCCs}$ are also expressed in mouse embryos (Table 1). The trophic factor platelet activating factor, PAF (1-o-alkyl-2acetyl-sn-glycerol-3-phosphocoline) has been shown to cause activation of a protein $G$ coupled receptor, phospholipase $\mathrm{C}$ and phosphatidylinositol 3-kinase (PIK3). PAF induces transient increases in intracellular $\mathrm{Ca}^{2+}, \mathrm{Ca}^{2+}$ influx, and an anion-driven outward current. The outward current was blocked by niflumic acid (NFA), a selective inhibitor of CaCCs, confirming the identity of the channel. Treatment of 1-cell stage embryos with NFA significantly reduced development to blastocyst stage (Li et al., 2007, 2009), arguing a role for $\mathrm{CaCC}$ in early mammalian embryonic development.

\section{Swell-Activated $\mathrm{Cl}^{-}$Channels and Transporters}

The cell volume regulation is a process that is highly controlled during embryo development. The cell volume regulation is mediated by the activity of swell-activated $\mathrm{Cl}^{-}$channels, which are expressed and active in mouse eggs. Early mouse embryos express chloride channels that are permeable to organic osmolytes and whose expression was shown to be cell-cycle dependent (Kolajova et al., 2001) (Table 1). Mouse zygotes can recover from swelling by activating these channels to release intracellular osmolytes out of the cell. Swell-activated channels are active during meiotic maturation and until the 8-cell or morula stage (Seguin and Baltz, 1997; Kolajova et al., 2001). Nevertheless, later studies showed that regulation of cell volume in pre-implantation embryos is a more complex phenomenon that involves more than one type of channels. These include the $\mathrm{Na}^{+} / \mathrm{H}^{+}$(NHE1) and the $\mathrm{HCO}_{3}^{-} / \mathrm{Cl}^{-}$(AE2) exchangers (Baltz and Zhou, 2012). Remarkably, these exchangers are inactive during meiotic maturation and are activated after fertilization. Other proteins involved in cell volume regulation after ovulation include the GLTY1 glycine transporter (Steeves et al., 2003) and the betaine and proline SIT1 transporter. SIT1 transporter regulates the accumulation of the organic osmolyte betaine after fertilization and it is mostly active in the 1- and 2-cell stages, whereas GLTY1 seems to be functionally active until the 4-cell stage (Baltz and Zhou, 2012).

\section{Potassium Channels}

\section{$\mathrm{Ca}^{2+}$ Activated Potassium Channels $\left(\mathrm{K}_{(\mathrm{Ca})}\right)$}

$\mathrm{Ca}^{2+}$-activated potassium channels $\left(\mathrm{K}_{(\mathrm{Ca})}\right)$ are tetramers and each subunit has six or seven transmembrane domains. They are divided in three groups depending of their unitary conductance: Big conductance (BK), intermediate conductance (IK) and small conductance $(\mathrm{SK})$. $\mathrm{K}_{(\mathrm{Ca})}$ channels are ubiquitously expressed in nearly every vertebrate excitable cell (Hille, 2001).

Fertilization in hamster eggs is marked by hyperpolarization spikes (Miyazaki and Igusa, 1981) that were related with the activity of $\mathrm{K}_{(\mathrm{Ca})}$ channels (Miyazaki and Igusa, 1982). The periodic hyperpolarizing pulses during fertilization reach to -70 to $-80 \mathrm{mV}$ from a resting potential of $-30 \mathrm{mV}$. They were abolished by injection of the $\mathrm{Ca}^{2+}$ chelator EGTA into eggs, suggesting $\mathrm{K}_{(\mathrm{Ca})}$ channels function (Georgiou et al., 1983; Igusa et al., 1983). The hyperpolarization responses after fertilization in mouse eggs are $\mathrm{Ca}^{2+}$ independent smaller in magnitude than those observed in hamster eggs. Thus, a different pool of channels activity during fertilization between the two species is suggested (Igusa et al., 1983).

Unfertilized human eggs showed hyperpolarization and increased basal current, following an injection of sperm factor, thimerosal (Homa and Swann, 1994), or in response to the $\mathrm{Ca}^{2+}$ ionophore A23187. Application of the ionophore in unfertilized eggs activated a bell-shaped current that was blocked by iberiotoxin, a selective blocker of BK channels. In agreement with $\mathrm{K}_{(\mathrm{Ca})}$ current, preloading oocytes with EGTA inhibited the current triggered by microinjection of $\mathrm{IP}_{3}$. Therefore, the mechanism of hyperpolarization in human eggs seems to be similar to hamster eggs (Gianaroli et al., 1994; Dale et al., 1996).

\section{Voltage-Gated Potassium Channels $\left(\mathrm{K}_{\mathrm{V}}\right)$}

In mouse eggs, a large conductance voltage-activated $\mathrm{K}^{+}$current was reported in unfertilized eggs. This current is not modulated by cytosolic $\mathrm{Ca}^{2+}$ and its activity is linked to the cell cycle, being high in M/G1 and low in S/G2 (Day et al., 1993; Table 1).

Endogenous voltage-activated $\mathrm{K}^{+}$currents, sensitive to Barium blockade, have been reported in Xenopus oocyte. However, their function and molecular identity remains elusive (Tokimasa and North, 1996).

\section{Intercellular Channels: Connexins}

Gap junctions are structures composed by intercellular channels which link the cytoplasm of adjacent cells and allow the exchange of metabolites, nutrients and signaling molecules. Gap junctions are aggregates of connexins (six) organized as large channels (connexons) between cells. In order to develop and mature, primordial oocytes need to establish direct cytoplasmic communication with the granulosa cells through gap junctions. In mice, the connexin responsible for the intercellular communication between oocytes and granulosa cells is connexin 37 (Cx37). The disruption of the gene encoding for $\mathrm{Cx} 37$ results in female infertility characterized by oocytes that fail to acquire meiotic competence and showed inappropriate formation of the corpora lutea. Ultimately, Cx37 KO females showed anovulation (Simon et al., 1997). Connexin 43 (Cx43) mediates interactions between granulosa cells and may be present in a minor fraction 
(if any) on the surface of oocytes. The absence of $\mathrm{Cx} 43$ in mice ovaries cause impaired postnatal folliculogenesis with failure to develop multiple layers of granulosa cells. Ovary-specific deletion of Cx43 gene generated oocytes that were morphologically abnormal and meiotically incompetent, therefore, cannot be fertilized (Ackert et al., 2001; Kidder and Mhawi, 2002). Connexin 26 ( Cx26) has been linked to the implantation process, however, in mice, the specific deletion of the gene encoding Cx26 in the uterine epithelium did not shown any obvious impairment of implantation (Winterhager and Kidder, 2015). In human cumulus cells, the addition of endothelin-1 has been shown to downregulate $\mathrm{Cx} 26$, blocking the resumption of meiosis and promoting the germinal-vesicle stage (Cui et al., 2018).

\section{CONCLUSIONS}

From the brief overview of the regulation and function of ionic conductances during fertilization, the egg-to-embryo transition and early embryogenesis, it is clear that channels play a fundamental role in mediating these processes. In Xenopus oocytes, the regulation of various ion channels at the PM and the ER membrane have been well characterized and their relative contribution to fertilization are fairly well defined. In contrast, there remains much to be learned about mammalian systems. For example, here, we have revisited the channels responsible for the electrical blockade to polyspermy, well-characterized in Xenopus but controversial in mammalian oocytes. Currently, the scientific evidence shows that for mammalian eggs, the blockade of polyspermy must be a combination of mechanisms, including changes in the membrane potential, reorganization of proteins expressed at the PM and even intracellular re-arrangements (Bianchi and Wright, 2016).

Current evidence collectively argue that $\mathrm{Ca}^{2+}$ influx is critical to maintain $\mathrm{Ca}^{2+}$ oscillations which are required for egg activation (Kline and Kline, 1992). However, the molecular identity of the channel(s) supporting $\mathrm{Ca}^{2+}$ influx during oocyte maturation and fertilization remains a puzzle that needs to be solved. In this regard, it is interesting to notice that current knowledge argue against a fundamental role for TRP channels during oocyte maturation and fertilization in Xenopus oocyte (see Table 1). In contrast, in mammals, members of the TRP channel family have been suggested to mediate $\mathrm{Ca}^{2+}$ influx during egg-to-embryo transition. Four main channels have been proposed to support $\mathrm{Ca}^{2+}$ influx in the egg: ORAI1, TRPV3, $\mathrm{Ca}_{\mathrm{v}}$ and TRPM7-like channels. Results obtained using genetically modified animals, argue against an essential role for ORAI, $\mathrm{Ca}_{\mathrm{v}}$ and TRPV3 at fertilization. Assessment of the role of a TRPM7-like channel awaits the generation of an oocyte-specific KO for TRPM7. Additionally, the possibility of a redundant system needs to be addressed. Orchestrated functioning of channels to promote $\mathrm{Ca}^{2+}$ influx might be the way to assure egg activation. Fertilization is an essential process in the evolution and maintenance of any sexually reproducing species. Therefore, it is likely that mammals have evolved multiple redundant mechanisms to assure $\mathrm{Ca}^{2+}$ influx at fertilization. These need to be sufficient to refill the stores and maintain the $\mathrm{Ca}^{2+}$ oscillations for extended periods of time. Current evidence argues that the egg is agnostic regarding the specific molecular pathway that mediates $\mathrm{Ca}^{2+}$ influx as long as it is able to maintain $\mathrm{Ca}^{2+}$ oscillations. It should be noted, however, that this $\mathrm{Ca}^{2+}$ influx needs to be balanced since overexpression of channels mediating $\mathrm{Ca}^{2+}$ influx such as ORAI1 disrupts early embryonic development (Lee et al., 2013). In this regard, the generation of genetically modified animals where a combination of channels are $\mathrm{KO}$ would be an interesting model to study $\mathrm{Ca}^{2+}$ signaling in oocyte physiology.

$\mathrm{Ca}^{2+}$ signals are fundamental to activate eggs at fertilization and to support pre-implantation embryo development. $\mathrm{Ca}^{2+}$ also plays a role in completion but not in the initiation of meiosis. $\mathrm{Ca}^{2+}$ signaling depends on $\mathrm{Ca}^{2+}$ influx and $\mathrm{Ca}^{2+}$ release from intracellular reservoirs such as the ER. In most cells, including gametes, $\mathrm{Ca}^{2+}$ influx and $\mathrm{Ca}^{2+}$ release are mediated by ion channels, in addition to other proteins. Figure 1 summarizes the current model for functional $\mathrm{Ca}^{2+}$ channels activity at the PM of mouse oocytes, eggs and early embryos. At the GV stage, spontaneous $\mathrm{Ca}^{2+}$ oscillations might be controlled by TRPM7-like and Cav channels (Carvacho et al., 2016). In ovulated eggs, TRPV3 contributes to $\mathrm{Ca}^{2+}$ influx (Carvacho et al., 2013). Additionally, $\mathrm{Ca}_{V}$ channels have been proposed to play a role in fertilization-triggered $\mathrm{Ca}^{2+}$ oscillations. However, the contribution of $\mathrm{Ca}_{\mathrm{v}}$ channels must be negligible, since no major differences in $\mathrm{Ca}^{2+}$ oscillations were observed between Cacnalh $^{-/-}$and Cacnalh ${ }^{-/+}$eggs (Bernhardt et al., 2015). After fertilization, pharmacological blockade of TRPM7-like channels suggest a fundamental role of the protein supporting $\mathrm{Ca}^{2+}$ oscillations and pre-implantation development (Carvacho et al., 2016; Bernhardt et al., 2017) (Figure 1). It was suggested that STIM and ORAI might mediate $\mathrm{Ca}^{2+}$ influx following store depletion in mouse GV oocytes. Mice lacking Stim1/2 and Orail did not show any difference in $\mathrm{ER} \mathrm{Ca}^{2+}$ stores in comparison to WT oocytes (Bernhardt et al., 2017). Nevertheless, the expression of native ORAI proteins has been shown by western blot (Cheon et al., 2013), therefore, ORAI in GV oocytes has been added to the model. Besides the aforementioned channels, we cannot rule out possible contributions of yet unknown channels, thus, this possibility is also indicated (channel X, Figure 1). Furthermore, one needs to interpret the $\mathrm{KO}$ studies with caution as they do not replicate the normal physiological state despite the fact that currently they provide the best tool available to directly assess the role of such channels. The $\mathrm{KO}$ of a channel in the oocyte is likely to remodel the expression and/or activity of other channels and/or transporters during oocyte growth and development using a feedback mechanism to ensure appropriate ionic and cellular homeostasis. As such phenotypes observed from mouse KO studies may not reflect the normal physiological state, despite the fact that they would conclusively define the absolute requirement for a particular gene. In that context, current data collectively argue that $\mathrm{Ca}^{2+}$ influx at fertilization in mammals is not mediated by rather multiple redundant pathways.

Studying ion channels in gametes remains technically challenging compared to somatic cells. Due to specialized biology of the gametes, researchers face difficulties in manipulating 
expression and controlling maternal effects. Different model systems are more amenable to certain experimental approaches than others. For example, given the large size of the oocyte, the Xenopus system is ideally suited for expression, imaging and biochemical analysis. However, these advantages create a challenge to visualize changes that occur deep in the oocyte. In that context, mammalian oocytes are more advantageous but are of limited use for detailed biochemical analysis. Therefore, a comparative approach building on knowledge from different systems is useful, as long as one remain cognizant of the need of individual species to evolve distinct mechanisms to maintain reproductive isolation.

\section{REFERENCES}

Abbott, A. L., and Ducibella, T. (2001). Calcium and the control of mammalian cortical granule exocytosis. Front. Biosci. 6, D792-D806. doi: 10.2741/Abbott

Ackert, C. L., Gittens, J. E., O’Brien, M. J., Eppig, J. J., and Kidder, G. M. (2001). Intercellular communication via connexin43 gap junctions is required for ovarian folliculogenesis in the mouse. Dev. Biol. 233, 258-270. doi: 10.1006/dbio.2001.0216

Bai, G. R., Yang, L. H., Huang, X. Y., and Sun, F. Z. (2006). Inositol 1,4,5trisphosphate receptor type 1 phosphorylation and regulation by extracellular signal-regulated kinase. Biochem. Biophys. Res. Commun. 348, 1319-1327. doi: 10.1016/j.bbrc.2006.07.208

Baltz, J. M., and Zhou, C. (2012). Cell volume regulation in mammalian oocytes and preimplantation embryos. Mol. Reprod. Dev. 79, 821-831. doi: $10.1002 / \mathrm{mrd} .22117$

Bataillon, E. (1919). Analyze de l'activation par la technique des oeufs nus et la polyspermie experimentale chez les batraciens. Ann. Sci. Nat. Zool. 10, 1-38.

Bement, W. M., and Capco, D. G. (1990). Transformation of the amphibian oocyte into the egg: structural and biochemical events. J. Electron Microsc. Tech. 16, 202-234. doi: 10.1002/jemt.1060160303

Bernhardt, M. L., Padilla-Banks, E., Stein, P., Zhang, Y., and Williams, C. J. (2017). Store-operated $\mathrm{Ca}^{2+}$ ) entry is not required for fertilizationinduced $\mathrm{Ca}(2+)$ signaling in mouse eggs. Cell Calcium 65, 63-72. doi: 10.1016/j.ceca.2017.02.004

Bernhardt, M. L., Zhang, Y., Erxleben, C. F., Padilla-Banks, E., McDonough, C. E., Miao, Y. L., et al. (2015). CaV3.2 T-type channels mediate $\mathrm{Ca}(2)(+)$ entry during oocyte maturation and following fertilization. J. Cell Sci. 128, 4442-4452. doi: $10.1242 /$ jcs. 180026

Berridge, M. J. (2005). Unlocking the secrets of cell signaling. Annu. Rev. Physiol. 67, 1-21. doi: 10.1146/annurev.physiol.67.040103.152647

Berridge, M. J., Lipp, P., and Bootman, M. D. (2000). The versatility and universality of calcium signalling. Nat. Rev. Mol. Cell Biol. 1, 11-21. doi: $10.1038 / 35036035$

Bianchi, E., and Wright, G. J. (2016). Sperm meets egg: the genetics of mammalian fertilization. Annu. Rev. Genet. 50, 93-111. doi: 10.1146/annurev-genet-121415-121834

Birnbaumer, L. (2015). From GTP and G proteins to TRPC channels: a personal account. J. Mol. Med. 93, 941-953. doi: 10.1007/s00109-0151328-5

Bobanovic, L. K., Laine, M., Petersen, C. C., Bennett, D. L., Berridge, M. J., Lipp, P., et al. (1999). Molecular cloning and immunolocalization of a novel vertebrate trp homologue from Xenopus. Biochem. J. 340 ( Pt 3), 593-599.

Bogeski, I., Al-Ansary, D., Qu, B., Niemeyer, B. A., Hoth, M., and Peinelt, C. (2010). Pharmacology of ORAI channels as a tool to understand their physiological functions. Expert Rev. Clin. Pharmacol. 3, 291-303. doi: 10.1586/ecp.10.23

Burkart, A. D., Xiong, B., Baibakov, B., Jiménez-Movilla, M., and Dean, J. (2012). Ovastacin, a cortical granule protease, cleaves ZP2 in the zona pellucida to prevent polyspermy. J. Cell Biol. 197, 37-44. doi: 10.1083/jcb.2011 12094

Busa, W. B., Ferguson, J. E., Joseph, S. K., Williamson, J. R., and Nuccitelli, R. (1985). Activation of frog (Xenopus laevis) eggs by inositol trisphosphate. I.

\section{AUTHOR CONTRIBUTIONS}

IC and KM wrote the first draft of the manuscript. MP designed the figure. IC, MP, TM, and KM critically revised the manuscript. IC and KM prepared the manuscript for submission. IC, MP, TM, and $\mathrm{KM}$ approved the final version to be published.

\section{ACKNOWLEDGMENTS}

We would like to thank Dr. Rafael A. Fissore for discussion and helpful suggestion to the manuscript. We thank Dr. Stephanie C. Stotz for critical revision of the manuscript.

Characterization of $\mathrm{Ca}^{2+}$ release from intracellular stores. J. Cell Biol. 101, 677-682. doi: 10.1083/jcb.101.2.677

Carvacho, I., Ardestani, G., Lee, H. C., McGarvey, K., Fissore, R. A., and LykkeHartmann, K. (2016). TRPM7-like channels are functionally expressed in oocytes and modulate post-fertilization embryo development in mouse. Sci. Rep. 6:34236. doi: 10.1038/srep34236

Carvacho, I., Lee, H. C., Fissore, R. A., and Clapham, D. E. (2013). TRPV3 channels mediate strontium-induced mouse-egg activation. Cell Rep. 5, 1375-1386. doi: 10.1016/j.celrep.2013.11.007

Catterall, W. A. (2011). Voltage-gated calcium channels. Cold Spring Harb. Perspect. Biol. 3:a003947. doi: 10.1101/cshperspect.a003947

Chen, C. C., Lamping, K. G., Nuno, D. W., Barresi, R., Prouty, S. J., Lavoie, J. L., et al. (2003). Abnormal coronary function in mice deficient in alphalH T-type $\mathrm{Ca}^{2+}$ channels. Science 302, 1416-1418. doi: 10.1126/science.1089268

Cheng, X., Jin, J., Hu, L., Shen, D., Dong, X. P., Samie, M. A., et al. (2010). TRP channel regulates EGFR signaling in hair morphogenesis and skin barrier formation. Cell 141, 331-343. doi: 10.1016/j.cell.2010.03.013

Cheon, B., Lee, H. C., Wakai, T., and Fissore, R. A. (2013). $\mathrm{Ca}^{2+}$ influx and the store-operated $\mathrm{Ca}^{2+}$ entry pathway undergo regulation during mouse oocyte maturation. Mol. Biol. Cell 24, 1396-1410. doi: 10.1091/mbc.e13-01-0065

Clapham, D. E. (1995). Calcium signaling. Cell 80, 259-268. doi: 10.1016/0092-8674(95)90408-5

Clapham, D. E. (2007). Calcium signaling. Cell 131, 1047-1058. doi: 10.1016/j.cell.2007.11.028

Courjaret, R., Hodeify, R., Hubrack, S., Ibrahim, A., Dib, M., Daas, S., et al. (2016). The Ca2+-activated $\mathrm{Cl}$ - channel Anol controls microvilli length and membrane surface area in the oocyte. J. Cell Sci. 129, 2548-2558. doi: $10.1242 /$ jcs. 188367

Courjaret, R., Hubrack, S., Daalis, A., Dib, M., and Machaca, K. (2013). The Xenopus TRPV6 homolog encodes a $\mathrm{Mg}(2+)$-permeant channel that is inhibited by interaction with TRPC1. J. Cell. Physiol. 228, 2386-2398. doi: $10.1002 / j c p .24411$

Cross, N. L. (1981). Initiation of the activation potential by an increase in intracellular calcium in eggs of the frog, Rana pipiens. Dev. Biol. 85, 380-384. doi: 10.1016/0012-1606(81)90269-4

Cross, N. L., and Elinson, R. P. (1980). A fast block to polyspermy in frogs mediated by changes in the membrane potential. Dev. Biol. 75, 187-198. doi: 10.1016/0012-1606(80)90154-2

Cui, L., Shen, J., Fang, L., Mao, X., Wang, H., and Ye, Y. (2018). Endothelin-1 promotes human germinal vesicle-stage oocyte maturation by downregulating connexin-26 expression in cumulus cells. Mol. Hum. Reprod. 24, 27-36. doi: $10.1093 /$ molehr/gax058

Dale, B. (2014). Is the idea of a fast block to polyspermy based on artifact? Biochem. Biophys. Res. Commun. 450, 1159-1165. doi: 10.1016/j.bbrc.2014.03.157

Dale, B., Fortunato, A., Monfrecola, V., and Tosti, E. (1996). A soluble sperm factor gates $\mathrm{Ca}\left({ }^{2+}\right)$-activated $\mathrm{K}^{+}$channels in human oocytes. J. Assist. Reprod. Genet. 13, 573-577. doi: 10.1007/BF02066611

Dascal, N., Snutch, T. P., Lübbert, H., Davidson, N., and Lester, H. A. (1986). Expression and modulation of voltage-gated calcium channels after RNA injection in Xenopus oocytes. Science 231, 1147-1150. doi: $10.1126 /$ science. 2418503 
Day, M. L., Johnson, M. H., and Cook, D. I. (1998). Cell cycle regulation of a T-type calcium current in early mouse embryos. Pflugers Arch. 436, 834-842. doi: $10.1007 / \mathrm{s} 004240050712$

Day, M. L., Pickering, S. J., Johnson, M. H., and Cook, D. I. (1993). Cell-cycle control of a large-conductance $\mathrm{K}^{+}$channel in mouse early embryos. Nature 365, 560-562. doi: 10.1038/365560a0

Demaurex, N., and Frieden, M. (2003). Measurements of the free luminal ER $\mathrm{Ca}\left({ }^{2+}\right)$ concentration with targeted "cameleon" fluorescent proteins. Cell Calcium 34, 109-119. doi: 10.1016/S0143-4160(03)00081-2

Ducibella, T., Huneau, D., Angelichio, E., Xu, Z., Schultz, R. M., Kopf, G. S., et al. (2002). Egg-to-embryo transition is driven by differential responses to $\mathrm{Ca}\left({ }^{2+}\right)$ oscillation number. Dev. Biol. 250, 280-291. doi: 10.1006/dbio.2002.0788

El Jouni, W., Haun, S., and Machaca, K. (2008). Internalization of plasma membrane $\mathrm{Ca}^{2+}$-ATPase during Xenopus oocyte maturation. Dev. Biol. 324, 99-107. doi: 10.1016/j.ydbio.2008.09.007

El Jouni, W., Jang, B., Haun, S., and Machaca, K. (2005). Calcium signaling differentiation during Xenopus oocyte maturation. Dev. Biol. 288, 514-525. doi: 10.1016/j.ydbio.2005.10.034

Ferris, C. D., Cameron, A. M., Bredt, D. S., Huganir, R. L., and Snyder, S. H. (1991). Inositol 1,4,5-trisphosphate receptor is phosphorylated by cyclic AMPdependent protein kinase at serines 1755 and 1589. Biochem. Biophys. Res. Commun. 175, 192-198. doi: 10.1016/S0006-291X(05)81219-7

Fontanilla, R. A., and Nuccitelli, R. (1998). Characterization of the sperm-induced calcium wave in Xenopus eggs using confocal microscopy. Biophys. J. 75, 2079-2087. doi: 10.1016/S0006-3495(98)77650-7

Foskett, J. K., White, C., Cheung, K. H., and Mak, D. O. (2007). Inositol trisphosphate receptor $\mathrm{Ca}^{2+}$ release channels. Physiol. Rev. 87, 593-658. doi: 10.1152/physrev.00035.2006

Fujiwara, T., Nakada, K., Shirakawa, H., and Miyazaki, S. (1993). Development of inositol trisphosphate-induced calcium release mechanism during maturation of hamster oocytes. Dev. Biol. 156, 69-79. doi: 10.1006/dbio.1993.1059

Gallo, A., Russo, G. L., and Tosti, E. (2013). T-type $\mathrm{Ca}^{2+}$ current activity during oocyte growth and maturation in the ascidian Styela plicata. PLoS ONE 8:e54604. doi: 10.1371/journal.pone.0054604

Georgiou, P., Bountra, C., Bland, K. P., and House, C. R. (1983). Calcium-evoked opening of potassium channels in hamster eggs. Q. J. Exp. Physiol. 68, 687-700. doi: 10.1113/expphysiol.1983.sp002758

Georgiou, P., Bountra, C., Bland, K. P., and House, C. R. (1984). Calcium action potentials in unfertilized eggs of mice and hamsters. Q. J. Exp. Physiol. 69, 365-380. doi: 10.1113/expphysiol.1984.sp002812

Gianaroli, L., Tosti, E., Magli, C., Iaccarino, M., Ferraretti, A. P., and Dale, B. (1994). Fertilization current in the human oocyte. Mol. Reprod. Dev. 38, 209-214. doi: 10.1002/mrd.1080380212

Gómez-Fernández, C., López-Guerrero, A. M., Pozo-Guisado, E., Álvarez, I. S., and Martín-Romero, F. J. (2012). Calcium signaling in mouse oocyte maturation: the roles of STIM1, ORAI1 and SOCE. Mol. Hum. Reprod. 18, 194-203. doi: 10.1093/molehr/gar071

Gomez-Fernandez, C., Pozo-Guisado, E., Ganan-Parra, M., Perianes, M. J., Alvarez, I. S., and Martin-Romero, F. J. (2009). Relocalization of STIM1 in mouse oocytes at fertilization: early involvement of store-operated calcium entry. Reproduction 138, 211-221. doi: 10.1530/REP-09-0126

Grey, R. D., Bastiani, M. J., Webb, D. J., and Schertel, E. R. (1982). An electrical block is required to prevent polyspermy in eggs fertilized by natural mating of Xenopus laevis. Dev. Biol. 89, 475-484. doi: 10.1016/0012-1606(82)90335-9

Grey, R. D., Wolf, D. P., and Hedrick, J. L. (1974). Formation and structure of the fertilization envelope in Xenopus laevis. Dev. Biol. 36, 44-61. doi: 10.1016/0012-1606(74)90189-4

Hachem, A., Godwin, J., Ruas, M., Lee, H. C., Ferrer Buitrago, M., Ardestani, G., et al. (2017). PLCzeta is the physiological trigger of the $\mathrm{Ca}\left({ }^{2+}\right)$ oscillations that induce embryogenesis in mammals but conception can occur in its absence. Development 144, 2914-2924. doi: 10.1242/dev.150227

Hagiwara, S., and Jaffe, L. A. (1979). Electrical properties of egg cell membranes. Annu. Rev. Biophys. Bioeng. 8, 385-416. doi: 10.1146/annurev.bb.08.060179.002125

Hamill, O. P., Marty, A., Neher, E., Sakmann, B., and Sigworth, F. J. (1981). Improved patch-clamp techniques for high-resolution current recording from cells and cell-free membrane patches. Pflugers Arch. 391, 85-100. doi: 10.1007/BF00656997
Hartzell, H. C. (1996). Activation of different Cl currents in Xenopus oocytes by Ca liberated from stores and by capacitative Ca influx. J. Gen. Physiol. 108, 157-175. doi: 10.1085/jgp.108.3.157

Hassold, T., and Hunt, P. (2001). To err (meiotically) is human: the genesis of human aneuploidy. Nat. Rev. Genet. 2, 280-291. doi: 10.1038/350 66065

Haun, S., Sun, L., Hubrack, S., Yule, D., and Machaca, K. (2012). Phosphorylation of the rat Ins $(1,4,5) P_{3}$ receptor at T930 within the coupling domain decreases its affinity to Ins $(1,4,5) P_{3}$. Channels $6,379-384$. doi: $10.4161 /$ chan. 21170

Hille, B. (2001). Ion Channels of Excitable Membranes. Sunderland, MA: Sinauer Associates, Inc.

Homa, S. T., and Swann, K. (1994). A cytosolic sperm factor triggers calcium oscillations and membrane hyperpolarizations in human oocytes. Hum. Reprod. 9, 2356-2361. doi: 10.1093/oxfordjournals.humrep.a138452

Hu, H. Z., Gu, Q., Wang, C., Colton, C. K., Tang, J., Kinoshita-Kawada, M., et al. (2004). 2-aminoethoxydiphenyl borate is a common activator of TRPV1, TRPV2, and TRPV3. J. Biol. Chem. 279, 35741-35748. doi: 10.1074/jbc.M404164200

Igusa, Y., Miyazaki, S., and Yamashita, N. (1983). Periodic hyperpolarizing responses in hamster and mouse eggs fertilized with mouse sperm. J. Physiol. 340, 633-647. doi: 10.1113/jphysiol.1983.sp014784

Inoue, D., Ohe, M., Kanemori, Y., Nobui, T., and Sagata, N. (2007). A direct link of the Mos-MAPK pathway to Erp1/Emi2 in meiotic arrest of Xenopus laevis eggs. Nature 446, 1100-1104. doi: 10.1038/nature05688

Jaffe, L. A. (1976). Fast block to polyspermy in sea urchin eggs is electrically mediated. Nature 261, 68-71. doi: 10.1038/261068a0

Jaffe, L. A., and Cross, N. L. (1984). Electrical properties of vertebrate oocyte membranes. Biol. Reprod. 30, 50-54. doi: 10.1095/biolreprod30.1.50

Jaffe, L. A., Cross, N. L., and Picheral, B. (1983). Studies of the voltage-dependent polyspermy block using cross-species fertilization of Amphibians. Dev. Biol. 98, 319-326. doi: 10.1016/0012-1606(83)90362-7

Jin, J., Desai, B. N., Navarro, B., Donovan, A., Andrews, N. C., and Clapham, D. E. (2008). Deletion of Trpm7 disrupts embryonic development and thymopoiesis without altering $\mathrm{Mg}^{2+}$ homeostasis. Science 322, 756-760. doi: $10.1126 /$ science.1163493

Jin, J., Wu, L. J., Jun, J., Cheng, X., Xu, H., Andrews, N. C., et al. (2012). The channel kinase, TRPM7, is required for early embryonic development. Proc. Natl. Acad. Sci. U.S.A. 109, E225-233. doi: 10.1073/pnas.1120033109

Jones, K. T., Carroll, J., and Whittingham, D. G. (1995). Ionomycin, thapsigargin, ryanodine, and sperm induced $\mathrm{Ca}^{2+}$ release increase during meiotic maturation of mouse oocytes. J. Biol. Chem. 270, 6671-6677. doi: 10.1074/jbc.270.12.6671

Kang, D., Hur, C. G., Park, J. Y., Han, J., and Hong, S. G. (2007). Acetylcholine increases $\mathrm{Ca}^{2+}$ influx by activation of CaMKII in mouse oocytes. Biochem. Biophys. Res. Commun. 360, 476-482. doi: 10.1016/j.bbrc.2007.06.083

Kashir, J., Deguchi, R., Jones, C., Coward, K., and Stricker, S. A. (2013). Comparative biology of sperm factors and fertilization-induced calcium signals across the animal kingdom. Mol. Reprod. Dev. 80, 787-815. doi: $10.1002 / \mathrm{mrd} .22222$

Kidder, G. M., and Mhawi, A. A. (2002). Gap junctions and ovarian folliculogenesis. Reproduction 123, 613-620. doi: 10.1530/rep.0.12 30613

Kishimoto, T. (2015). Entry into mitosis: a solution to the decades-long enigma of MPF. Chromosoma 124, 417-428. doi: 10.1007/s00412-0150508-y

Kline, D., and Kline, J. T. (1992). Thapsigargin activates a calcium influx pathway in the unfertilized mouse egg and suppresses repetitive calcium transients in the fertilized egg. J. Biol. Chem. 267, 17624-17630.

Kline, J. T., and Kline, D. (1994). Regulation of intracellular calcium in the mouse egg: evidence for inositol trisphosphate-induced calcium release, but not calcium-induced calcium release. Biol. Reprod. 50, 193-203. doi: 10.1095/biolreprod50.1.193

Koh, S., Lee, K., Wang, C., Cabot, R. A., and Machaty, Z. (2009). STIM1 regulates store-operated $\mathrm{Ca}^{2+}$ entry in oocytes. Dev. Biol. 330, 368-376. doi: 10.1016/j.ydbio.2009.04.007

Kolajova, M., Hammer, M. A., Collins, J. L., and Baltz, J. M. (2001). Developmentally regulated cell cycle dependence of swelling-activated anion channel activity in the mouse embryo. Development 128, 3427-3434. 
Kuruma, A., and Hartzell, H. C. (2000). Bimodal control of a $\mathrm{Ca}^{2+}$ activated $\mathrm{Cl}^{-}$channel by different $\mathrm{Ca}^{2+}$ signals. J. Gen. Physiol. 115, 59-80. doi: 10.1085/jgp.115.1.59

Larabell, C., and Nuccitelli, R. (1992). Inositol lipid hydrolysis contributes to the $\mathrm{Ca}^{2+}$ wave in the activating egg of Xenopus laevis. Dev. Biol. 153, 347-355. doi: 10.1016/0012-1606(92)90119-2

Lee, B., Palermo, G., and Machaca, K. (2013). Downregulation of store-operated $\mathrm{Ca}^{2+}$ entry during mammalian meiosis is required for the egg-to-embryo transition. J. Cell Sci. 126(Pt 7), 1672-1681. doi: 10.1242/jcs.121335

Lee, B., Vermassen, E., Yoon, S. Y., Vanderheyden, V., Ito, J., Alfandari, D., et al. (2006). Phosphorylation of IP3R1 and the regulation of $\left[\mathrm{Ca}^{2+}\right]$ i responses at fertilization: a role for the MAP kinase pathway. Development 133, 4355-4365. doi: $10.1242 /$ dev. 02624

Lee, H. C., Yoon, S. Y., Lykke-Hartmann, K., Fissore, R. A., and Carvacho, I. (2016). TRPV3 channels mediate $\mathrm{Ca}^{2+}$ influx induced by 2-APB in mouse eggs. Cell Calcium 59, 21-31. doi: 10.1016/j.ceca.2015.12.001

Lee, K., Wang, C., and Machaty, Z. (2012). STIM1 is required for $\mathrm{Ca}^{2+}$ signaling during mammalian fertilization. Dev. Biol. 367, 154-162. doi: $10.1016 /$ j.ydbio.2012.04.028

Lewis, R. S. (1999). Store-operated calcium channels. Adv. Second Messenger Phosphoprotein Res. 33, 279-307. doi: 10.1016/S1040-7952(99)80014-7

Li, Y., Day, M. L., and O'Neill, C. (2007). Autocrine activation of ion currents in the two-cell mouse embryo. Exp. Cell Res. 313, 2786-2794. doi: 10.1016/j.yexcr.2007.05.022

Li, Y., O'Neill, C., and Day, M. L. (2009). Activation of a chloride channel by a trophic ligand is required for development of the mouse preimplantation embryo in vitro. Biol. Reprod. 81, 759-767. doi: 10.1095/biolreprod.108. 074567

Liu, J., and Maller, J. L. (2005). Calcium elevation at fertilization coordinates phosphorylation of XErp1/Emi2 by Plx1 and CaMK II to release metaphase arrest by cytostatic factor. Curr. Biol. 15, 1458-1468. doi: 10.1016/j.cub.2005.07.030

Lorca, T., Cruzalegui, F. H., Fesquet, D., Cavadore, J. C., Mery, J., Means, A., et al. (1993). Calmodulin-dependent protein kinase II mediates inactivation of MPF and CSF upon fertilization of Xenopus eggs. Nature 366, 270-273. doi: $10.1038 / 366270 \mathrm{a} 0$

Lu, Y., Reddy, R., Ferrer Buitrago, M., Vander Jeught, M., Neupane, J., De Vos, W. H., et al. (2018). Strontium fails to induce $\mathrm{Ca}^{2+}$ release and activation in human oocytes despite the presence of functional TRPV3 channels. Human Reproduction Open 2018, 1-11. doi: 10.1093/hropen/hoy005

Machaca, K. (2004). Increased sensitivity and clustering of elementary $\mathrm{Ca}^{2+}$ release events during oocyte maturation. Dev. Biol. 275 170-182. doi: 10.1016/j.ydbio.2004.08.004

Machaca, K. (2007). $\mathrm{Ca}^{2+}$ signaling differentiation during oocyte maturation. J. Cell. Physiol. 213, 331-340. doi: 10.1002/jcp.21194

Machaca, K., and Haun, S. (2000). Store-operated calcium entry inactivates at the germinal vesicle breakdown stage of Xenopus meiosis. J. Biol. Chem. 275, 38710-38715. doi: 10.1074/jbc.M007887200

Machaca, K., and Haun, S. (2002). Induction of maturation-promoting factor during Xenopus oocyte maturation uncouples $\mathrm{Ca}^{2+}$ store depletion from storeoperated $\mathrm{Ca}^{2+}$ entry. J. Cell Biol. 156, 75-85. doi: 10.1083/jcb.200110059

Machaca, K., Qu, Z., Kuruma, A., Hartzell, H. C., and McCarty, N. (2001). “The endogenous calcium-activated $\mathrm{Cl}$ channel in Xenopus oocytes: a physiologically and biophysically rich model system," in Calcium Activates Chloride Channels, ed C. M. Fuller (San Diego, CA: Academic Press), 3-39.

Machaty, Z., Wang, C., Lee, K., and Zhang, L. (2017). Fertility: store-operated $\mathrm{Ca}\left({ }^{2+}\right)$ entry in germ cells: role in egg activation. Adv. Exp. Med. Biol. 993, 577-593. doi: 10.1007/978-3-319-57732-6_29

Maeno, T. (1959). Electrical characteristics and activation potential of Bufo eggs. J. Gen. Physiol. 43, 139-157. doi: 10.1085/jgp.43.1.139

Malathi, K., Kohyama, S., Ho, M., Soghoian, D., Li, X., Silane, M., et al. (2003). Inositol 1,4,5-trisphosphate receptor (type 1) phosphorylation and modulation by Cdc2. J. Cell. Biochem. 90, 1186-1196. doi: 10.1002/jcb.10720

McNally, B. A., and Prakriya, M. (2012). Permeation, selectivity and gating in store-operated CRAC channels. J. Physiol. 590, 4179-4191. doi: 10.1113/jphysiol.2012.233098

Mehlmann, L., and Kline, D. (1994). Regulation of intracellular calcium in the mouse egg: calcium release in response to sperm or inositol trisphosphate is enhanced after meiotic maturation. Biol. Reprod. 51, 1088-1098. doi: 10.1095/biolreprod51.6.1088

Miao, Y. L., Stein, P., Jefferson, W. N., Padilla-Banks, E., and Williams, C. J. (2012). Calcium influx-mediated signaling is required for complete mouse egg activation. Proc. Natl. Acad. Sci. U.S.A. 109, 4169-4174. doi: $10.1073 /$ pnas.1112333109

Miyazaki, S. (1995). Calcium signalling during mammalian fertilization. Ciba Found. Symp. 188, 235-247; discussion: 247-251.

Miyazaki, S., and Igusa, Y. (1981). Fertilization potential in golden hamster eggs consists of recurring hyperpolarizations. Nature 290, 702-704. doi: $10.1038 / 290702 \mathrm{a} 0$

Miyazaki, S., and Igusa, Y. (1982). Ca-mediated activation of a K current at fertilization of golden hamster eggs. Proc. Natl. Acad. Sci. U.S.A. 79, 931-935. doi: 10.1073/pnas.79.3.931

Miyazaki, S., Shirakawa, H., Nakada, K., and Honda, Y. (1993). Essential role of the inositol 1,4,5-trisphosphate receptor/ $\mathrm{Ca}^{2+}$ release channel in $\mathrm{Ca}^{2+}$ waves and $\mathrm{Ca}^{2+}$ oscillations at fertilization of mammalian eggs. Dev. Biol. 158, 62-78. doi: 10.1006/dbio.1993.1168

Miyazaki, S., Yuzaki, M., Nakada, K., Shirakawa, H., Nakanishi, S., Nakade, S., et al. (1992). Block of $\mathrm{Ca}^{2+}$ wave and $\mathrm{Ca}^{2+}$ oscillation by antibody to the inositol 1,4,5-trisphosphate receptor in fertilized hamster eggs. Science 257, 251-255. doi: 10.1126/science. 1321497

Mochida, S., and Hunt, T. (2007). Calcineurin is required to release Xenopus egg extracts from meiotic M phase. Nature 449, 336-340. doi: 10.1038/nature06121

Mohri, T., Shirakawa, H., Oda, S., Sato, M. S., Mikoshiba, K., and Miyazaki, S. (2001). Analysis of $\mathrm{Mn}\left({ }^{2+}\right) / \mathrm{Ca}\left({ }^{2+}\right)$ influx and release during $\mathrm{Ca}\left({ }^{2+}\right)$ oscillations in mouse eggs injected with sperm extract. Cell Calcium 29, 311-325. doi: 10.1054/ceca.2000.0196

Morin, N., Abrieu, A., Lorca, T., Martin, F., and Doree, M. (1994). The proteolysisdependent metaphase to anaphase transition: calcium/calmodulin-dependent protein kinase II mediates onset of anaphase in extracts prepared from unfertilized Xenopus eggs. EMBO J. 13, 4343-4352.

Nader, N., Kulkarni, R. P., Dib, M., and Machaca, K. (2013). How to make a good egg!: the need for remodeling of oocyte $\mathrm{Ca}\left({ }^{2+}\right)$ signaling to mediate the egg-toembryo transition. Cell Calcium 53, 41-54. doi: 10.1016/j.ceca.2012.11.015

Nigg, E. A. (1991). The substrates of the cdc2 kinase. Semin. Cell Biol. 2, 261-270.

Nishiyama, T., Yoshizaki, N., Kishimoto, T., and Ohsumi, K. (2007). Transient activation of calcineurin is essential to initiate embryonic development in Xenopus laevis. Nature 449, 341-345. doi: 10.1038/nature06136

Nuccitelli, R., Yim, D. L., and Smart, T. (1993). The sperm-induced Ca2+ wave following fertilization of the Xenopus egg requires the production of Ins $(1,4$, 5)P3. Dev. Biol. 158, 200-212. doi: 10.1006/dbio.1993.1179

Okamoto, H., Takahashi, K., and Yamashita, N. (1977). Ionic currents through the membrane of the mammalian oocyte and their comparison with those in the tunicate and sea urchin. J. Physiol. 267, 465-495. doi: 10.1113/jphysiol.1977.sp011822

Parys, J. B., and Bezprozvanny, I. (1995). The inositol trisphosphate receptor of Xenopus oocytes. Cell Calcium 18, 353-363. doi: 10.1016/0143-4160(95)90051-9

Parys, J. B., Sernett, S. W., DeLisle, S., Snyder, P. M., Welsh, M. J., and Campbell, K. P. (1992). Isolation, characterization, and localization of the inositol 1,4,5trisphosphate receptor protein in Xenopus laevis oocytes. J. Biol. Chem. 267, 18776-18782.

Peier, A. M., Reeve, A. J., Andersson, D. A., Moqrich, A., Earley, T. J., Hergarden, A. C., et al. (2002). A heat-sensitive TRP channel expressed in keratinocytes. Science 296, 2046-2049. doi: 10.1126/science. 1073140

Peres, A. (1986). Resting membrane potential and inward current properties of mouse ovarian oocytes and eggs. Pflugers Arch. 407, 534-540. doi: $10.1007 / \mathrm{BF} 00657512$

Peres, A. (1987). The calcium current of mouse egg measured in physiological calcium and temperature conditions. J. Physiol. 391, 573-588. doi: 10.1113/jphysiol.1987.sp016757

Powers, R. D., and Tupper, J. T. (1974). Some electrophysiological and permeability properties of the mouse egg. Dev. Biol. 38, 320-331. doi: 10.1016/0012-1606(74)90010-4

Prakriya, M., Feske, S., Gwack, Y., Srikanth, S., Rao, A., and Hogan, P. G. (2006). Orail is an essential pore subunit of the CRAC channel. Nature 443, 230-233. doi: 10.1038 /nature05122 
Ramirez, D., Gonzalez, W., Fissore, R. A., and Carvacho, I. (2017). Conotoxins as tools to understand the physiological function of voltage-gated calcium $(\mathrm{CaV})$ channels. Mar. Drugs 15:313. doi: 10.3390/md15100313

Rauh, N. R., Schmidt, A., Bormann, J., Nigg, E. A., and Mayer, T. U. (2005). Calcium triggers exit from meiosis II by targeting the APC/C inhibitor XErp1 for degradation. Nature 437, 1048-1052. doi: 10.1038/nature04093

Runft, L. L., Jaffe, L. A., and Mehlmann, L. M. (2002). Egg activation at fertilization: where it all begins. Dev. Biol. 245, 237-254. doi: 10.1006/dbio.2002.0600

Saunders, C. M., Larman, M. G., Parrington, J., Cox, L. J., Royse, J., Blayney, L. M., et al. (2002). PLC zeta: a sperm-specific trigger of $\mathrm{Ca}\left({ }^{2+}\right)$ oscillations in eggs and embryo development. Development 129, 3533-3544.

Schindl, R., Fritsch, R., Jardin, I., Frischauf, I., Kahr, H., Muik, M., et al. (2012). Canonical transient receptor potential (TRPC) 1 acts as a negative regulator for vanilloid TRPV6-mediated $\mathrm{Ca}^{2+}$ influx. J. Biol. Chem. 287, 35612-35620. doi: 10.1074/jbc.M112.400952

Schmidt, A., Duncan, P. I., Rauh, N. R., Sauer, G., Fry, A. M., Nigg, E. A., et al. (2005). Xenopus polo-like kinase Plx1 regulates XErp1, a novel inhibitor of APC/C activity. Genes Dev. 19, 502-513. doi: 10.1101/gad.320705

Schmidt, A., Rauh, N. R., Nigg, E. A., and Mayer, T. U. (2006). Cytostatic factor: an activity that puts the cell cycle on hold. J. Cell Sci. 119(Pt 7), 1213-1218. doi: $10.1242 /$ jcs.02919

Schroeder, B. C., Cheng, T., Jan, Y. N., and Jan, L. Y. (2008). Expression cloning of TMEM16A as a calcium-activated chloride channel subunit. Cell 134, 1019-1029. doi: 10.1016/j.cell.2008.09.003

Seguin, D. G., and Baltz, J. M. (1997). Cell volume regulation by the mouse zygote: mechanism of recovery from a volume increase. Am. J. Physiol. 272(6 Pt 1), C1854-C1861. doi: 10.1152/ajpcell.1997.272.6.C1854

Shiina, Y., Kaneda, M., Matsuyama, K., Tanaka, K., Hiroi, M., and Doi, K. (1993). Role of the extracellular $\mathrm{Ca}^{2+}$ on the intracellular $\mathrm{Ca}^{2+}$ changes in fertilized and activated mouse oocytes. J. Reprod. Fertil. 97, 143-150. doi: 10.1530/jrf.0.0970143

Shim, A. H., Tirado-Lee, L., and Prakriya, M. (2015). Structural and functional mechanisms of CRAC channel regulation. J. Mol. Biol. 427, 77-93. doi: 10.1016/j.jmb.2014.09.021

Simon, A. M., Goodenough, D. A., Li, E., and Paul, D. L. (1997). Female infertility in mice lacking connexin 37. Nature 385, 525-529. doi: 10.1038/385525a0

Smith, G. D., Gunthorpe, M. J., Kelsell, R. E., Hayes, P. D., Reilly, P., Facer, P., et al. (2002). TRPV3 is a temperature-sensitive vanilloid receptor-like protein. Nature 418, 186-190. doi: 10.1038/nature00894

Smith, L. D. (1989). The induction of oocyte maturation: transmembrane signaling events and regulation of the cell cycle. Development 107, 685-699.

Steeves, C. L., Hammer, M. A., Walker, G. B., Rae, D., Stewart, N. A., and Baltz, J. M. (2003). The glycine neurotransmitter transporter GLYT1 is an organic osmolyte transporter regulating cell volume in cleavage-stage embryos. Proc. Natl. Acad. Sci. U.S.A. 100, 13982-13987. doi: 10.1073/pnas.23345 37100

Stricker, S. A. (1999). Comparative biology of calcium signaling during fertilization and egg activation in animals. Dev. Biol. 211, 157-176. doi: 10.1006/dbio.1999.9340

Sun, L., Haun, S., Jones, R. C., Edmondson, R. D., and Machaca, K. (2009). Kinase-dependent regulation of IP3-dependent $\mathrm{Ca}^{2+}$ release during oocyte maturation. J. Biol. Chem. 284, 20184-20196. doi: 10.1074/jbc.M109.004515

Sun, L., Yu, F., Ullah, A., Hubrack, S., Daalis, A., Jung, P., et al. (2011). Endoplasmic reticulum remodeling tunes IP3-dependent $\mathrm{Ca}^{2+}$ release sensitivity PLOS ONE 6:e27928. doi: 10.1371/journal.pone.0027928

Swann, K. (1992). Different triggers for calcium oscillations in mouse eggs involve a ryanodine-sensitive calcium store. Biochem. J. 287(Pt 1), 79-84. doi: 10.1042/bj2870079

Swann, K., and Lai, F. A. (2016). The sperm phospholipase C-zeta and $\mathrm{Ca}^{2+}$ signalling at fertilization in mammals. Biochem. Soc. Trans. 44, 267-272. doi: 10.1042/BST20150221

Taylor, C. W., and Tovey, S. C. (2010). IP(3) receptors: toward understanding their activation. Cold Spring Harb. Perspect. Biol. 2:a004010. doi: 10.1101/cshperspect.a004010

Terasaki, M., Runft, L. L., and Hand, A. R. (2001). Changes in organization of the endoplasmic reticulum during Xenopus oocyte maturation and activation. Mol. Biol. Cell 12, 1103-1116. doi: 10.1091/mbc.12.4.1103
Tokimasa, T., and North, R. A. (1996). Effects of barium, lanthanum and gadolinium on endogenous chloride and potassium currents in Xenopus oocytes. J. Physiol. 496(Pt 3), 677-686. doi: 10.1113/jphysiol.1996. sp021718

Tosti, E., Boni, R., and Cuomo, A. (2000). Ca $\left({ }^{2+}\right)$ current activity decreases during meiotic progression in bovine oocytes. Am. J. Physiol. Cell Physiol. 279, C1795-C1800. doi: 10.1152/ajpcell.2000.279.6.C1795

Tosti, E., Boni, R., Gallo, A., and Silvestre, F. (2013). Ion currents modulating oocyte maturation in animals. Syst. Biol. Reprod. Med. 59, 61-68. doi: 10.3109/19396368.2012.758790

Tung, J. J., Hansen, D. V., Ban, K. H., Loktev, A. V., Summers, M. K., Adler, J. R. III, et al. (2005). A role for the anaphase-promoting complex inhibitor Emi2/XErp1, a homolog of early mitotic inhibitor 1, in cytostatic factor arrest of Xenopus eggs. Proc. Natl. Acad. Sci. U.S.A 102, 4318-4323. doi: 10.1073/pnas.0501108102

Tunquist, B. J., and Maller, J. L. (2003). Under arrest: cytostatic factor (CSF)mediated metaphase arrest in vertebrate eggs. Genes Dev. 17, 683-710. doi: 10.1101/gad.1071303

Tyler, A. (1941). Artificial parthenogenesis. Biol. Rev. 16, 291-336. doi: 10.1111/j.1469-185X.1941.tb01105.x

Tyler, A., Monroy, A., Kao, C. Y., and Grundfest, H. (1956). Membrane potential and resistance of the starfish egg before and after fertilization. Biol. Bull. 111, 153-177. doi: 10.2307/1539191

Ullah, G., Jung, P., and Machaca, K. (2007). Modeling $\mathrm{Ca}\left({ }^{2+}\right)$ signaling differentiation during oocyte maturation. Cell Calcium 42, 556-564. doi: 10.1016/j.ceca.2007.01.010

Vanderheyden, V., Devogelaere, B., Missiaen, L., De Smedt, H., Bultynck, G., and Parys, J. B. (2009). Regulation of inositol 1,4,5-trisphosphate-induced $\mathrm{Ca}^{2+}$ release by reversible phosphorylation and dephosphorylation. Biochim. Biophys. Acta 1793, 959-970. doi: 10.1016/j.bbamcr.2008.12.003

Vieira, A., and Miller, D. J. (2006). Gamete interaction: is it species-specific? Mol. Reprod. Dev. 73, 1422-1429. doi: 10.1002/mrd.20542

Vig, M., Beck, A., Billingsley, J. M., Lis, A., Parvez, S., Peinelt, C., et al. (2006). CRACM1 multimers form the ion-selective pore of the CRAC channel. Curr. Biol. 16, 2073-2079. doi: 10.1016/j.cub.2006.08.085

Vig, M., DeHaven, W. I., Bird, G. S., Billingsley, J. M., Wang, H., Rao, P. E., et al. (2008). Defective mast cell effector functions in mice lacking the CRACM1 pore subunit of store-operated calcium release-activated calcium channels. Nat. Immunol. 9, 89-96. doi: 10.1038/ni1550

Wakai, T., Vanderheyden, V., and Fissore, R. A. (2011). $\mathrm{Ca}^{2+}$ signaling during mammalian fertilization: requirements, players, and adaptations. Cold Spring Harb. Perspect. Biol. 3:a006767. doi: 10.1101/cshperspect.a006767

Wakai, T., Vanderheyden, V., Yoon, S. Y., Cheon, B., Zhang, N., Parys, J. B., et al. (2012). Regulation of inositol 1,4,5-trisphosphate receptor function during mouse oocyte maturation. J. Cell. Physiol. 227, 705-717. doi: 10.1002/jcp. 22778

Wakayama, T., Perry, A. C., Zuccotti, M., Johnson, K. R., and Yanagimachi, R. (1998). Full-term development of mice from enucleated oocytes injected with cumulus cell nuclei. Nature 394, 369-374. doi: 10.1038/ 28615

Wang, C., Lee, K., Gajdocsi, E., Papp, A. B., and Machaty, Z. (2012). Orail mediates store-operated $\mathrm{Ca}^{2+}$ entry during fertilization in mammalian oocytes. Dev. Biol. 365, 414-423. doi: 10.1016/j.ydbio.2012.03.007

Westendorf, J. M., Rao, P. N., and Gerace, L. (1994). Cloning of cDNAs for Mphase phosphoproteins recognized by the MPM2 monoclonal antibody and determination of the phosphorylated epitope. Proc. Natl. Acad. Sci. U.S.A. 91, 714-718. doi: 10.1073/pnas.91.2.714

Whitaker, M. (2006). Calcium at fertilization and in early development. Physiol. Rev. 86, 25-88. doi: 10.1152/physrev.00023.2005

Whittingham, D. G., and Siracusa, G. (1978). The involvement of calcium in the activation of mammalian oocytes. Exp. Cell Res. 113, 311-317. doi: 10.1016/0014-4827(78)90371-3

Winterhager, E., and Kidder, G. M. (2015). Gap junction connexins in female reproductive organs: implications for women's reproductive health. Hum. Reprod. Update 21, 340-352. doi: 10.1093/humupd/dmv007

Wolf, D. P. (1974). The cortical granule reaction in living eggs of the toad, Xenopus laevis. Dev. Biol. 36, 62-71. doi: 10.1016/0012-1606(74)90190-0 
Wu, L. J., Sweet, T. B., and Clapham, D. E. (2010). International Union of Basic and Clinical Pharmacology. LXXVI. Current progress in the mammalian TRP ion channel family. Pharmacol. Rev. 62, 381-404. doi: 10.1124/pr.110.002725

Xu, H., Ramsey, I. S., Kotecha, S. A., Moran, M. M., Chong, J. A., Lawson, D., et al. (2002). TRPV3 is a calcium-permeable temperature-sensitive cation channel. Nature 418, 181-186. doi: 10.1038/nature00882

$\mathrm{Xu}, \mathrm{Y} . \mathrm{R}$., and Yang, W. X. (2017). Calcium influx and sperm-evoked calcium responses during oocyte maturation and egg activation. Oncotarget 8, 89375-89390. doi: 10.18632/oncotarget.19679

Yamashita, N. (1982). Enhancement of ionic currents through voltage-gated channels in the mouse oocyte after fertilization. J. Physiol. 329, 263-280. doi: 10.1113/jphysiol.1982.sp014302

Yang, P., and Zhu, M. X. (2014). Trpv3. Handb. Exp. Pharmacol. 222, 273-291. doi: 10.1007/978-3-642-54215-2_11

Yang, Y. D., Cho, H., Koo, J. Y., Tak, M. H., Cho, Y., Shim, W. S., et al. (2008). TMEM16A confers receptor-activated calcium-dependent chloride conductance. Nature 455, 1210-1215. doi: 10.1038/nature 07313

Yoshida, S. (1983). Permeation of divalent and monovalent cations through the ovarian oocyte membrane of the mouse. J. Physiol. 339, 631-642. doi: 10.1113/jphysiol.1983.sp014739

Ypey, D. L., and DeFelice, L. J. (2000). The Patch-Clamp Technique Explained and Exercised with the use of Simple Electrical Equivalent Circuits. Available online at: http://mdc.custhelp.com/euf/assets/images/KB864_ModelCells.pdf

Yu, F., Sun, L., and Machaca, K. (2009). Orail internalization and STIM1 clustering inhibition modulate SOCE inactivation during meiosis. Proc. Natl. Acad. Sci. U.S.A. 106, 17401-17406. doi: 10.1073/pnas.0904651106

Yu, F., Sun, L., and Machaca, K. (2010). Constitutive recycling of the store-operated $\mathrm{Ca}^{2+}$ channel Orail and its internalization during meiosis. J. Cell Biol. 191, 523-535. doi: $10.1083 /$ jcb. 201006022
Yu, Y., Nomikos, M., Theodoridou, M., Nounesis, G., Lai, F. A., and Swann, K. (2012). PLCzeta causes $\mathrm{Ca}\left({ }^{2+}\right)$ oscillations in mouse eggs by targeting intracellular and not plasma membrane $\mathrm{PI}(4,5) \mathrm{P}(2)$. Mol. Biol. Cell 23, 371-380. doi: 10.1091/mbc.e11-08-0687

Yuan, J. P., Kim, M. S., Zeng, W., Shin, D. M., Huang, G., Worley, P. F., et al. (2009). TRPC channels as STIM1-regulated SOCs. Channels 3, 221-225. doi: 10.4161/chan.3.4.9198

Zeng, W., Yuan, J. P., Kim, M. S., Choi, Y. J., Huang, G. N., Worley, P. F., et al. (2008). STIM1 gates TRPC channels, but not Orail, by electrostatic interaction. Mol. Cell 32, 439-448. doi: 10.1016/j.molcel.2008.09.020

Zhang, L., Chao, C. H., Jaeger, L. A., Papp, A. B., and Machaty, Z (2018). Calcium oscillations in fertilized pig oocytes are associated with repetitive interactions between STIM1 and ORAI1. Biol. Reprod. 98, 510-519. doi: 10.1093/biolre/ioy016

Zhang, N., Yoon, S. Y., Parys, J. B., and Fissore, R. A. (2015). Effect of M-phase kinase phosphorylations on type 1 inositol 1,4,5-trisphosphate receptor-mediated $\mathrm{Ca}^{2+}$ responses in mouse eggs. Cell Calcium 58, 476-488. doi: 10.1016/j.ceca.2015.07.004

Conflict of Interest Statement: The authors declare that the research was conducted in the absence of any commercial or financial relationships that could be construed as a potential conflict of interest.

Copyright (c) 2018 Carvacho, Piesche, Maier and Machaca. This is an open-access article distributed under the terms of the Creative Commons Attribution License (CC $B Y)$. The use, distribution or reproduction in other forums is permitted, provided the original author(s) and the copyright owner are credited and that the original publication in this journal is cited, in accordance with accepted academic practice. No use, distribution or reproduction is permitted which does not comply with these terms. 